\title{
Efficacy and safety of dual SGLT 1/2 inhibitor sotagliflozin in type 1 diabetes: meta-analysis of randomised controlled trials
}

Check for updates

\author{
Giovanni Musso, ${ }^{1}$ Roberto Gambino, ${ }^{2}$ Maurizio Cassader, ${ }^{2}$ Elena Paschetta ${ }^{1}$
}

${ }^{1}$ Humanitas University

Gradenigo Hospital, 8 Corso

Regina Margherita, 10132

Turin, Italy

${ }^{2}$ Laboratory of Diabetes and Metabolic Disorders, Department of Medical

Sciences, University of Turin, Turin, Italy

Correspondence to: G Musso giovanni_musso@yahoo.it (ORCID 0000-0002-8569-2872) Additional material is published online only. To view please visit the journal online.

Cite this as: BMJ 2019;365:11328 http://dx.doi.org/10.1136/bmj.l1328

Accepted: 12 March 2019

\begin{abstract}
OBJECTIVE

To assess the efficacy and safety of dual sodium glucose cotransporter (SGLT) $1 / 2$ inhibitor sotagliflozin in type 1 diabetes mellitus.

DESIGN

Meta-analysis of randomised controlled trials.

DATA SOURCES

Medline; Cochrane Library; Embase; international meeting abstracts; international and national clinical trial registries; and websites of US, European, and Japanese regulatory authorities, up to 10 January 2019.

ELIGIBILITY CRITERIA FOR SELECTING STUDIES

Randomised controlled trials evaluating the effect of sotagliflozin versus active comparators or placebo on glycaemic and non-glycaemic outcomes and on adverse events in type 1 diabetes in participants older than 18. Three reviewers extracted data for study characteristics, outcomes of interest, and risk of bias and summarised strength of evidence using the grading of recommendations assessment, development, and evaluation approach. Main outcomes were pooled using random effects models.

RESULTS

Of 739 records identified, six randomised placebo controlled trials ( $n=3238$, duration $4-52$ weeks) were
\end{abstract}

\section{WHAT IS ALREADY KNOWN ON THIS TOPIC}

In patients with type 1 diabetes mellitus, $30 \%$ achieve glycaemic targets and are encumbered by unwanted effects of insulin, namely hypoglycaemia and weight gain; severe hypoglycaemia, in particular, is the main factor limiting optimal glucose control and a risk factor for adverse events in diabetes

Sotagliflozin is a novel, dual sodium glucose co-transport (SGLT) $1 / 2$ inhibitor that inhibits intestinal glucose absorption as well as renal glucose reabsorption; this mechanism of action could blunt postprandial glycaemic excursions and glycaemic variability, eventually reducing the need for bolus insulin corrections and hypoglycaemic risk

Sotagliflozin has completed phase III clinical development in type 1 diabetes, but the evidence regarding its efficacy and safety in this population has not been systematically reviewed

\section{WHAT THIS STUDY ADDS}

Compared with placebo, sotagliflozin improves glycaemic and non-glycaemic outcomes (including markers of diabetic nephropathy) and reduces the incidence of hypoglycaemia and of severe hypoglycaemia

Diabetic ketoacidosis (DKA) is the main adverse event associated with sotagliflozin treatment, and its risk depends on initial $\mathrm{HbA1c}$ levels in patients and reduction of the basal insulin dose during treatment; sotagliflozin is also associated with an increased risk of genital tract infections and diarrhoea, but not of urinary tract infections

Current evidence on long term outcomes is limited by the short duration of individual trials included. Sotagliflozin reduced levels of glycated haemoglobin (HbA1c; weighted mean difference $-0.34 \%$ (95\% confidence interval $-0.41 \%$ to $-0.27 \%), P<0.001)$; fasting plasma glucose $(-16.98$ $\mathrm{mg} / \mathrm{dL},-22.1$ to $-11.9 ; 1 \mathrm{mg} / \mathrm{dL}=0.0555 \mathrm{mmol} / \mathrm{L}$ ) and two hour-postprandial plasma glucose $(-39.2$ $\mathrm{mg} / \mathrm{dL},-50.4$ to -28.1$)$; and daily total, basal, and bolus insulin dose $(-8.99 \%,-10.93 \%$ to $-7.05 \%$; $-8.03 \%,-10.14 \%$ to $-5.93 \% ;-9.14 \%,-12.17 \%$ to $-6.12 \%$; respectively). Sotagliflozin improved time in range (weighted mean difference $9.73 \%$, $6.66 \%$ to $12.81 \%$ ) and other continuous glucose monitoring parameters, and reduced body weight (-3.54\%, $-3.98 \%$ to $-3.09 \%)$, systolic blood pressure ( $-3.85 \mathrm{~mm} \mathrm{Hg},-4.76$ to -2.93$)$, and albuminuria (albumin:creatinine ratio $-14.57 \mathrm{mg} / \mathrm{g},-26.87$ to -2.28 ). Sotagliflozin reduced hypoglycaemia (weighted mean difference -9.09 events per patient year, -13.82 to -4.36 ) and severe hypoglycaemia (relative risk $0.69,0.49$ to 0.98 ). However, the drug increased the risk of ketoacidosis (relative risk 3.93, 1.94 to 7.96$)$, genital tract infections $(3.12,2.14$ to 4.54), diarrhoea $(1.50,1.08$ to 2.10$)$, and volume depletion events $(2.19,1.10$ to 4.36). Initial HbA1c and basal insulin dose adjustment were associated with the risk of diabetic ketoacidosis. A sotagliflozin dose of $400 \mathrm{mg} /$ day was associated with a greater improvement in most glycaemic and non-glycaemic outcomes than the $200 \mathrm{mg} /$ day dose, without increasing the risk of adverse events. The quality of evidence was high to moderate for most outcomes, but low for major adverse cardiovascular events and all cause death. The relatively short duration of trials prevented assessment of long term outcomes.

\section{CONCLUSIONS}

In type 1 diabetes, sotagliflozin improves glycaemic and non-glycaemic outcomes and reduces hypoglycaemia rate and severe hypoglycaemia. The risk of diabetic ketoacidosis could be minimised by appropriate patient selection and down-titration of the basal insulin dose.

\section{Introduction}

Type 1 diabetes mellitus affects 1.5 million people in the United States alone and its prevalence is continuously rising, partly because over $10 \%$ of patients initially presumed to have type 2 diabetes at diagnosis subsequently show evidence of islet autoimmunity and progress to insulin dependence later on. ${ }^{12}$ The achievement and maintenance of glycaemic goals in type 1 diabetes has proven both difficult and hazardous. In the T1D Exchange clinic registry, the average level of glycated haemoglobin (HbA1c) was $8 \%$, only $30 \%$ of patients with type 1 diabetes achieved an HbA1c goal of $7 \%$, and severe 
hypoglycaemia occurred in up to $20 \%$ of patients per year. ${ }^{3}$ Similarly, in the Diabetes Complications and Control Trial, patients with type 1 diabetes with HbA1c levels within target showed a 2.9-fold increased cardiovascular mortality, ${ }^{4}$ and patients in the intensive intervention group escalated back to an $\mathrm{HbA1c}$ of $8 \%$ in the years following the trial. ${ }^{5}$

Insulin is the mainstay of treatment for type 1 diabetes, but has unwanted effects, including hypoglycaemia and weight gain. ${ }^{6}$ Severe hypoglycaemia in particular is the main factor limiting optimal glucose control in the disease; it is frequent, adds costs to diabetes management, and is a strong predictor of adverse vascular and non-vascular outcomes and death. ${ }^{6-9}$ None of the adjunctive treatments approved (that is, pramlintide) or recently proposed for type 1 diabetes (that is, metformin, incretin analogues, and sodium glucose cotransporter (SGLT) 2 inhibitors) has reduced the incidence of hypoglycaemia and severe hypoglycaemia, which remain the major unresolved issue in the management of these patients. ${ }^{10-20}$

SGLT1 is responsible for glucose absorption in the proximal intestine, and missense mutations in SGLT1 gene have been associated with protection from glucose intolerance, obesity, and cardiometabolic risk in population based studies. ${ }^{21}$ Sotagliflozin (LX4211, SAR439954) is a novel, first-in-class, dual inhibitor of SGLT1 and SGLT2; while SGLT2 inhibition reduces glucose reabsorption in the renal tubule, SGLT1 inhibition decreases glucose absorption in the intestine. This dual mechanism of action could offer incremental benefits over selective SGLT2 inhibitors ${ }^{22}$

\section{thebmi Visual Abstract 0 Sotagliflozin in type 1 diabetes Investigating published effectiveness and safety of the dual SGLT1/2 inhibitor \\ D4] Systematic review and meta-analysis} Improves glycaemic and non-glycaemic outcomes, including

6 Summary

Data sources

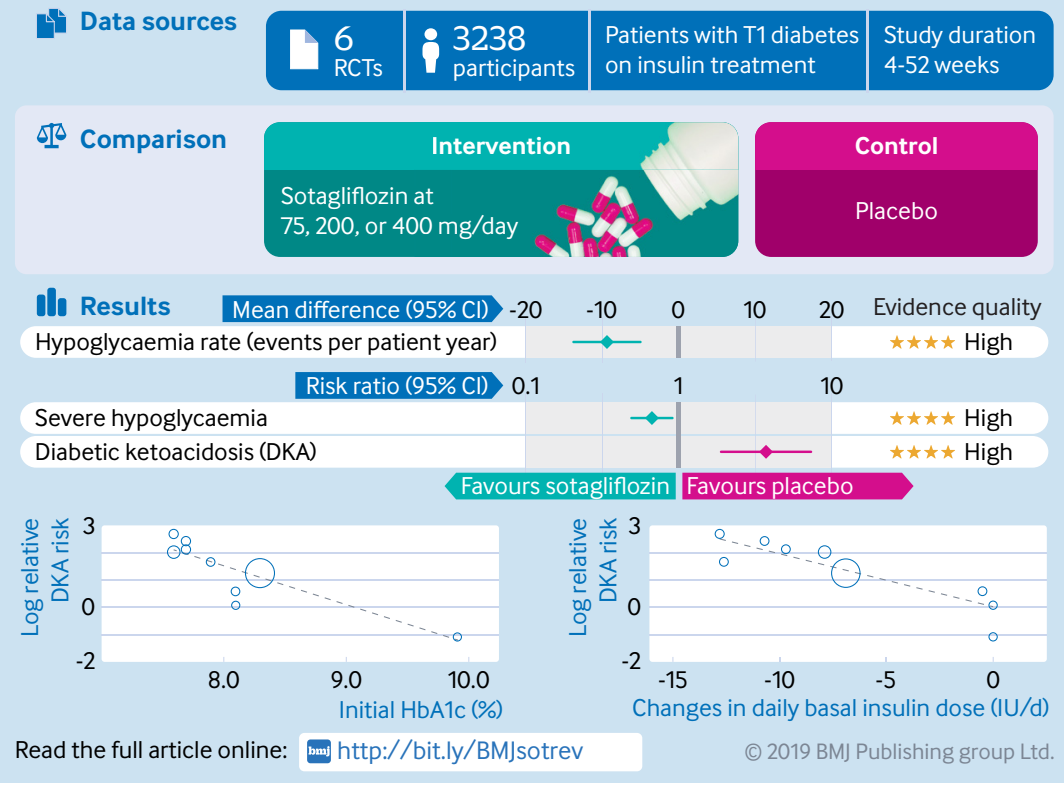
markers of diabetic nephropathy. Reduces hypoglycaemia an severe hypoglycaemia. Increases the risk of diabetic ketoacidosis, which depends on initial HbA1c and basal insulin dose reduction by blunting postprandial glycaemic excursions and glycaemic variability, lowering the need for bolus insulin correction doses, and eventually reducing hypoglycaemic risk. ${ }^{23}$ Furthermore, reduced glucose absorption in the proximal intestine increases glucose delivery to the distal intestine, stimulating incretin glucagon-like peptide-1 (GLP-1). ${ }^{24}$ In preclinical models, the increased release of incretin has enhanced weight loss and counteracted glucagon induced ketogenesis, ${ }^{25}$ which could reduce the risk of diabetic ketoacidosis. ${ }^{23-25}$

Sotagliflozin has recently reached phase III development in patients with type 1 diabetes ${ }^{26-31}$ but randomised controlled trials evaluating this drug have not been systematically reviewed. To clarify the evidence base of this novel approach, we conducted a meta-analysis of randomised controlled trials evaluating the efficacy and safety of sotagliflozin in adults with type 1 diabetes.

\section{Methods}

\section{Data sources and searches}

We searched English and non-English language publications up to 10 January 2019 on the following databases and international and national clinical trial registries: Ovid Medline, Ovid Medline Epub Ahead of Print, Ovid Medline In-Process, Embase, Cochrane Database of Systematic Reviews, Epistemonikos, ClinicalTrials.gov, Cochrane CENTRAL Register of Controlled Trials, World Health Organization International Clinical Trials Registry Platform, European Union Clinical Trials Register, International Standard Randomised Controlled Trial Number registry, Australian New Zealand Clinical Trials Registry, and 19 national clinical trial registries (full list of clinical trial registries provided in supplementary text). No language restrictions were applied. We also searched the US Food and Drug Administration, ${ }^{32}$ European Medicines Agency, ${ }^{33}$ and Japanese Pharmaceutical and Medical Devices Agency ${ }^{34}$ websites and drug manufacturers' websites ${ }^{35}{ }^{36}$ for relevant documents, and the American Diabetes Association and European Association for the Study of Diabetes meeting abstracts, which were subjected to the same assessment as regular articles.

Additionally, we emailed authors of relevant papers to verify results and methodological quality of retrieved articles, and drug manufacturers to inquire about further published and unpublished trials. We manually scanned reference lists from trials, review articles, and reports to identify any other relevant data. Search terms were "sodium glucose co-transport 1/2 inhibitors," "dual sodium-glucose transport inhibitors," "SGLT1/2 inhibitors," "SGLT1 inhibitors," "SGLT2 inhibitors," "SGLT1/2 inhibitor," "sotagliflozin," “LX4211,” “LP802034,” “SAR439954,” “Zynquista,” "management,” “therapy,” “treatment," “trial,” "diabetes," and "type 1 diabetes" (examples of online strategy run are provided in supplementary text).

\section{Study selection}

Inclusion criteria included English and non-English (French, Spanish, Portuguese, German, Chinese, 
Japanese, Korean) articles of randomised controlled trials. Trial participants were aged 18 and older of any sex or ethnic origin, and the trials compared sotagliflozin with placebo or active comparators as an adjunct treatment to insulin in type 1 diabetes. We excluded non-human studies, non-randomised trials, letters or case reports, and articles not reporting outcomes of interest or primary data (editorials, reviews).

\section{Outcome measures}

We grouped evaluated outcomes into three broad groups: glycaemic efficacy outcomes, non-glycaemic outcomes, and safety outcomes. Glycaemic efficacy outcomes were:

- $\quad$ Changes in glycated haemoglobin (HbA1c) from baseline (primary outcome)

- Changes in levels of fasting plasma glucose

- Changes in two hour postprandial glycaemia (2h-PPG), as measured during an oral glucose tolerance test or a standardised mixed meal tolerance test. Many studies have linked postprandial glucose excursions to the risk of cardiovascular disease and report that targeting postprandial glycaemia rather than fasting plasma glucose lowers cardiovascular risk ${ }^{37} 38$

- Changes in total, basal, and bolus insulin dose (expressed as \% of the initial insulin dose)

- Effect of SGLT1/2 inhibitors on daily urinary glucose excretion

- Continuous glucose monitoring parameters. Continuous glucose monitoring provides additional information to $\mathrm{HbA1c}$ and has been recently recommended for all adults with type 1 diabetes and approved by the US Food and Drug Administration Advisory Committee. ${ }^{39}$ We therefore assessed the following metrics of continuous glucose monitoring (described in the supplementary text): time in range (\%), average daily glucose, standard deviation around average daily glucose, and mean amplitude of glucose excursion. ${ }^{40}$

Non-glycaemic outcome measures evaluated were changes in body weight, systolic and diastolic blood pressure; renal outcomes, defined as changes in estimated glomerular filtration rate (eGFR) and in albuminuria (expressed as urinary albumin:creatinine ratio, ACR), or need for renal replacement therapy; and changes in plasma lipids (triglyceride, low density lipoprotein-cholesterol, and high density lipoproteincholesterol).

Safety measures were severe hypoglycaemia and any hypoglycaemia, diabetic ketoacidosis (definitions provided in the supplementary text), urinary tract infections, genital tract infections, other infections, gastrointestinal symptoms, major adverse cardiovascular events (MACE; cardiovascular death, myocardial infarction, stroke, admission owing to heart failure or unstable angina, or coronary revascularisation), cancer (overall and type specific), amputation, bone fracture, volume depletion, renal events, acidosis related events, drug induced liver injury, venous thromboembolism, serious adverse events, adverse events leading to treatment discontinuation, and all cause mortality. Volume depletion, acidosis related events, renal events, and serious adverse events were defined according to the Medical Dictionary for Regulatory Activities preferred items version $14.0^{41}$ (supplementary text). We also planned to investigate whether the risk of diabetic ketoacidosis varied across different modes of insulin delivery (that is, MDI or CSI). All measures of dispersion were converted to standard deviations.

\section{Data extraction and risk of bias assessment}

Two reviewers (GM, RG) extracted data independently and in duplicate by using a predesigned data collection form, based on the Cochrane handbook for systematic reviews of intervention; discrepancies were arbitrated by a third reviewer and resolved by consensus. The agreement between the two reviewers for selection and validity assessment of trials was scored by the $\kappa$ coefficient.

The quality of randomised controlled trials was assessed by the Cochrane Collaboration risk of bias tool. ${ }^{42}$ We also assessed sponsorship bias, which we included in the risk of bias tool. The 2018 Agency for Healthcare Research and Quality recommendations caution against equating industry sponsorship with high risk of bias and automatically downgrading the evidence for industry sponsorship. ${ }^{43}$ Therefore, for all included trials, we systematically assessed a prespecified list of eight items in trial designing, conducting, and reporting, which have been empirically linked to the risk of biased outcomes in industry funded trials and are not captured by the six domains of the risk of bias tool ${ }^{44-50}$ (supplementary table 1).

\section{Data synthesis, analysis, and grading of evidence}

The analysis was carried out in accordance with the Cochrane handbook of systematic reviews of interventions $^{42}$ using Stata release 11.2 (StataCorp, College Station, TX, USA) and RevMan version 5.3.5 (Nordic Cochrane Center, Copenhagen, Denmark), ${ }^{51}$ and was reported according to PRISMA guidelines ${ }^{52}$ (preferred reporting items for systematic reviews and metaanalyses; see supplementary appendix). Treatments were evaluated on an intention-to-treat principle.

We calculated weighted mean differences and 95\% confidence intervals for continuous outcomes using an inverse variance random effects model. For dichotomous outcomes, we calculated risk ratios and 95\% confidence intervals by using the random effects Mantel-Haenszel approach with significance set at $\mathrm{P}=0.05$. We conservatively used a priori a random effects model assuming a substantial variability in treatment effect size across studies. Statistical heterogeneity was assessed using the $\mathrm{I}^{2}$ statistic: with $\mathrm{I}^{2}$ values of $50 \%$ or over, we planned to explore individual study characteristics, and characteristics of subgroups of the main body of evidence. ${ }^{53}$ 
We planned to conduct sensitivity analyses by repeating the analysis with alternative effect measures (odds ratio $v$ relative risk), pooling methods (Peto $v$ Mantel-Hanszel ${ }^{54}$ ), and statistical models (fixed $v$ random effects) by excluding randomised controlled trials where we imputed values and randomised controlled trials at high risk of bias in any domains of the risk of bias tool. We also planned a priori subgroup analyses to explore potential effects on outcome measures of the following conditions: treatment duration ( $\leq 12 v>12$ weeks), initial HbA1c levels $(\geq 8 \% v<8 \%$ ), duration of diabetes $(<20 v \geq 20$ years), background treatment (pretreatment insulin optimisation $v$ stable insulin treatment), and presence and severity of renal dysfunction.

When trials evaluated different sotagliflozin doses, we planned to present data separately for each dose and to split sample size of the placebo group evenly among different dose comparisons. ${ }^{42}$ We explored interactions between different sotagliflozin doses and all outcomes primarily by comparing different dose groups within head-to-head trials (within-trial approach); we planned to verify robustness of this approach by also using across-trial comparison and meta-regression. Although the across-trial approach has a higher risk of ecological bias, it has a higher power than the within-trial approach, thus allowing us to rule out dose-response interactions with higher confidence. ${ }^{55}$

When eight or more comparisons were available, the effect of different SGLT1/2 inhibitor doses, baseline HbA1c, treatment duration, and diabetes duration on each outcome were assessed by meta-regression analysis (random effects model, within-study variance estimated with the unrestricted maximum likelihood method). Furthermore, the dose variable in the regression equation was treated categorically, with the starting dose coded as the baseline amount and each doubling of a drug dose considered to be a single increment increase. Publication bias was examined by funnel plots and the Egger test.

We used the grading of recommendations assessment, development, and evaluation (GRADE) approach to summarise the strength of evidence at outcome level and determine confidence in summary estimates for clinically relevant comparisons and outcomes. ${ }^{5657}$ Three reviewers graded inconsistency, risk of bias, indirectness, imprecision, and publication bias for evidence related to the following areas: glycaemic efficacy (outcomes: HbA1c, fasting plasma glucose, 2h-PPG, time in range), non-glycaemic efficacy (outcomes: body weight, systemic blood pressure, eGFR, albuminuria), and adverse events (outcomes: hypoglycaemia, severe hypoglycaemia, diabetic ketoacidosis, urinary and genital tract infections, diarrhoea, MACE, serious adverse events, adverse events leading to discontinuation, and mortality). We planned to manage missing data by contacting via email the corresponding authors. Where this method was unsuccessful, we planned to follow the approach described in Cochrane handbook of systematic reviews of intervention (chapter 7.6-7.8 and 16.1.3 ${ }^{42}$; see supplementary text).

\section{Patient and public involvement}

No patients were involved in the definition of the research question or the outcome measures, and interpretation or writing up of results. Data relating to the impact of the intervention on participants' quality of life were not extracted. Where possible, results of this meta-analysis will be disseminated to the patient community or individual patients and families through the investigators of this meta-analysis.

\section{Results}

The flow of study selection is reported in figure 1. At the end of selection, six placebo controlled randomised trials (duration 4-52 weeks) enrolling 3238 participants with type 1 diabetes were included in the meta-analysis ${ }^{26-31} 5859$ (main characteristics reported in supplementary table 1). We excluded 12 phase I trials conducted in individuals without diabetes, 18 trials enrolling patients with type 2 diabetes (four completed, 14 active), and one trial enrolling patients without diabetes but with congestive heart failure (main characteristics of excluded trials reported in supplementary table 2). All included randomised controlled trials compared sotagliflozin with placebo on background insulin treatment. Three trials $^{28} 3031$ compared different sotagliflozin doses (75, 200, or $400 \mathrm{mg} /$ day) with placebo. Overall, 10 comparisons were available for the meta-analysis. Two trials adopted insulin dose optimisation (target: fasting plasma glucose $80-130 \mathrm{mg} / \mathrm{dL}$ and $2 \mathrm{~h}-\mathrm{PPG}$ $>180 \mathrm{mg} / \mathrm{dL} ; 1 \mathrm{mg} / \mathrm{dL}=0.0555 \mathrm{mmol} / \mathrm{L}$ ) during the six weeks preceding randomisation. ${ }^{30} 31$ Two trials excluded patients with impaired renal function (eGFR $\left.<60 \mathrm{~mL} / \mathrm{min} / 1.73 \mathrm{~m}^{2}\right),{ }^{26}{ }^{28}$ and four trials excluded patients with moderate-to-severe renal impairment $\left(\mathrm{eGFR}<45 \mathrm{~mL} / \mathrm{min} / 1.73 \mathrm{~m}^{2}\right){ }^{27} 293031$

Participants' baseline characteristics were equally balanced between the study arms; in all randomised controlled trials, dropout rates were generally low and balanced across arms. No trial used the lastobservation-carried-forward approach to impute missing observations, which were imputed as nonresponse for dichotomous outcomes. For continuous outcomes, we used mixed effects model-for-repeatedmeasures statistics, based on the restricted maximum likelihood method for estimation. Two trials were partly funded by non-profit organisations, ${ }^{26} 27$ while a pharmaceutical company entirely funded four trials. However, we did not find any evidence of high risk of biased outcomes in trial design, conduct, and reporting. The overall quality was good for all included trials. The risk of bias summary for individual trials and the risk of bias graph for each item across included trials are detailed in supplementary table 1 and summarised in supplementary figures 1-2. The analysis of funnel plots and the Egger test $(\mathrm{P}>0.67$ for all outcomes) did not find any evidence of publication bias (supplementary figure 3). No values had to be imputed for the meta-analysis during data extraction. The agreement between the two reviewers was 0.96 


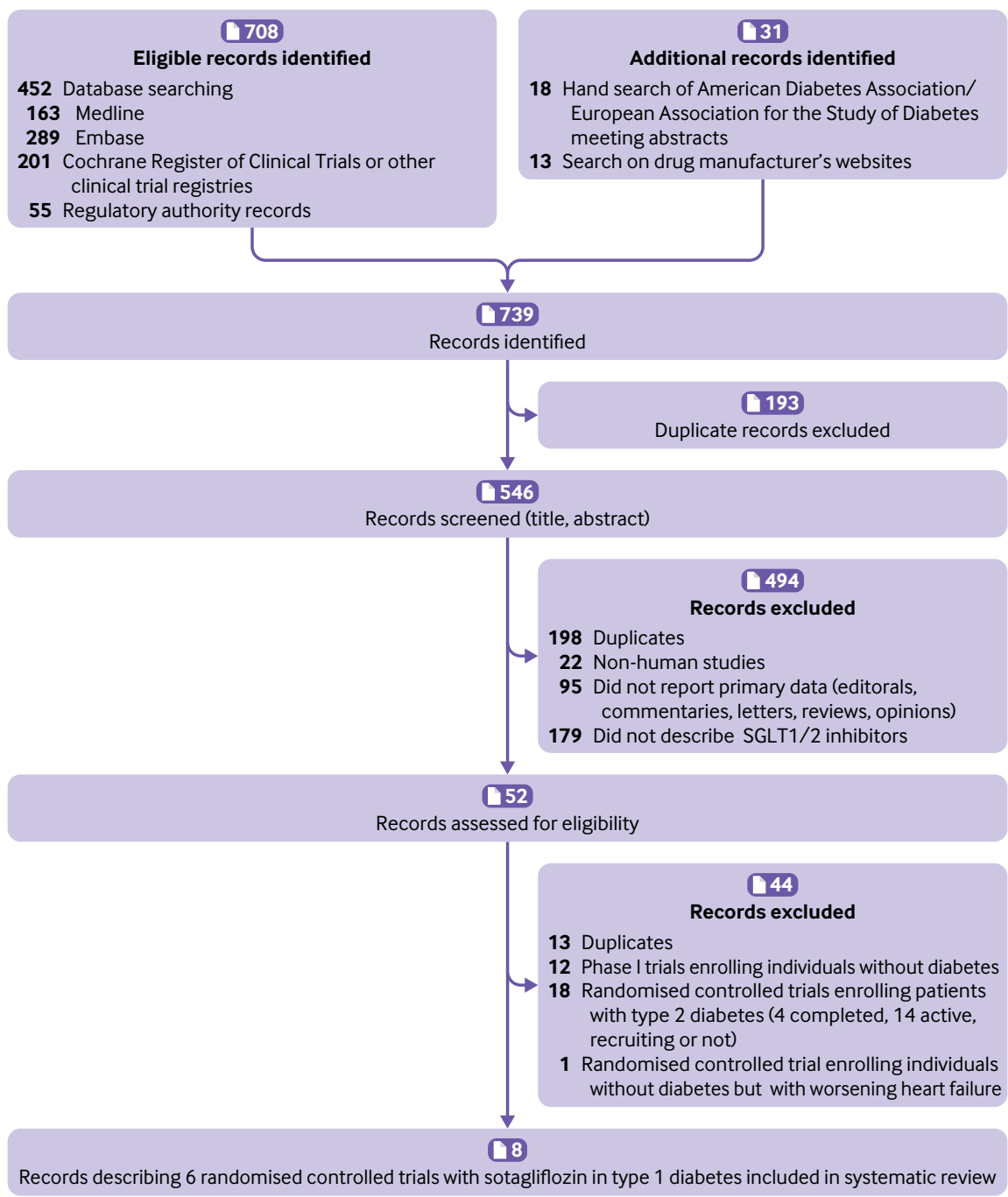

Fig 1 | Flow diagram of evidence acquisition during study

for study selection and 0.89 for quality assessment of trials.

\section{Glycaemic efficacy outcomes HbA1c}

Compared with placebo, sotagliflozin treatment was associated with a significant reduction in $\mathrm{HbA} 1 \mathrm{c}$ levels (weighted mean difference $-0.34 \%$, 95\% confidence interval $-0.41 \%$ to $-0.27 \%, \mathrm{P}<0.001, \mathrm{I}^{2}=20 \%, 10$ comparisons, 3238 participants; fig 2). We saw little heterogeneity in the meta-analysis, suggesting a consistent drug effect. Subgroup and meta-regression analysis showed that the effect was independent of trial duration $(\beta=0.110, \mathrm{P}=0.28)$ and baseline $\mathrm{HbA} 1 \mathrm{c}$ $(\beta=0.119, P=0.38$; supplementary table 3$)$. HbA1c reduction with sotagliflozin at $400 \mathrm{mg} /$ day was higher than with $200 \mathrm{mg} /$ day (supplementary table 4).

\section{Fasting plasma glucose and two hour-postprandial} plasma glucose

Sotagliflozin significantly reduced fasting plasma glucose (weighted mean difference $-16.98 \mathrm{mg} / \mathrm{dL}$, $95 \%$ confidence interval -22.09 to $-11.86, \mathrm{P}<0.001$,
$\mathrm{I}^{2}=6 \%, \quad 10$ comparisons, 3238 participants) and 2h-PPG $(-39.24 \mathrm{mg} / \mathrm{dL},-50.42$ to -28.06 , $\mathrm{P}<0.001$, $\mathrm{I}^{2}=20 \%$, nine comparisons, 539 participants; fig 2). We saw little heterogeneity in the meta-analysis, suggesting a consistent drug effect. The effect was independent of trial duration and baseline HbA1c (supplementary table 3).

\section{Continuous glucose monitoring parameters}

Four randomised controlled trials evaluated continuous glucose monitoring parameters. ${ }^{26} 273031$ Compared with placebo, sotagliflozin significantly increased time in range (weighted mean difference 9.73\%, 95\% confidence interval $6.66 \%$ to $12.81 \%, \mathrm{P}<0.001, \mathrm{I}^{2}=24 \%$, six comparisons, 398 participants) and reduced average daily glucose $(-15.09 \mathrm{mg} / \mathrm{dL},-21.40$ to -8.79 , $\mathrm{P}<0.001, \mathrm{I}^{2}=28 \%$, five comparisons, 312 participants), standard deviation around average daily glucose (-6.68 $\mathrm{mg} / \mathrm{dL},-10.59$ to $-2.77, \mathrm{P}<0.001, \mathrm{I}^{2}=0 \%$, five comparisons, 311 participants), and mean amplitude of glucose excursion $(-19.52 \mathrm{mg} / \mathrm{dL},-28.91$ to -10.54 , $\mathrm{P}<0.001, \mathrm{I}^{2}=0 \%$, five comparisons, 311 participants; supplementary figure 4). We saw little heterogeneity in 


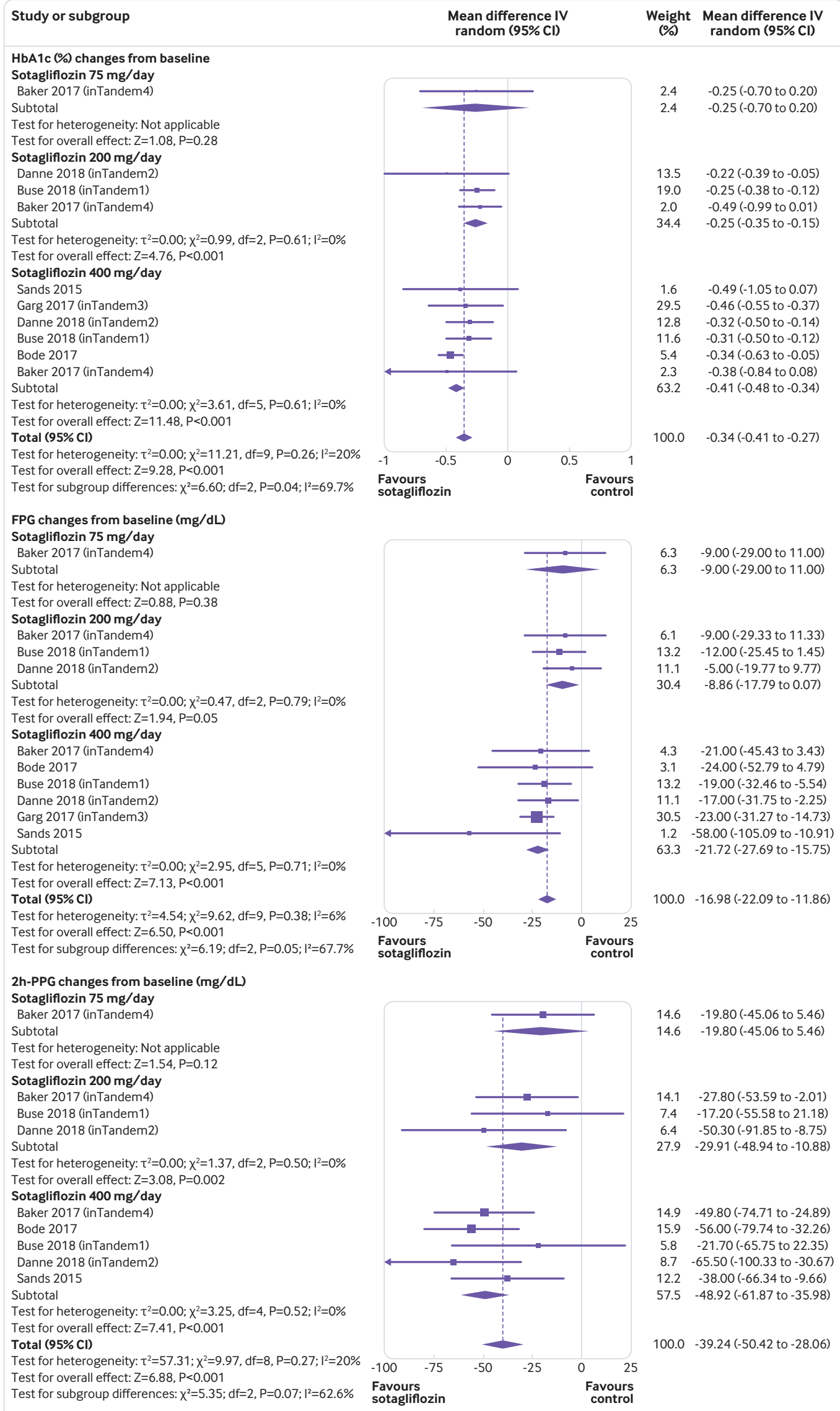

Fig 2 | Forest plot comparing effect of sotagliflozin versus placebo on $\mathrm{HbA1C}(\%)$, fasting plasma glucose (FPG), and two hour-postprandial plasma glucose (2h-PPG). $1 \mathrm{mg} / \mathrm{dL}=0.0555 \mathrm{mmol} / \mathrm{L}$. IV=inverse variance 
the meta-analysis, suggesting a consistent drug effect. Sotagliflozin at $400 \mathrm{mg} /$ day was significantly more effective than $200 \mathrm{mg} /$ day at improving time in range, average daily glucose, and mean amplitude of glucose excursion (supplementary table 4).

\section{Daily total, basal, and bolus insulin dose}

Compared with placebo, sotagliflozin reduced daily total (weighted mean difference $-8.99 \%$, 95\% confidence interval $-10.93 \%$ to $-7.05 \%, \mathrm{P}<0.001$, $\mathrm{I}^{2}=33 \%$, 10 comparisons, 3238 participants), basal $\left(-8.03 \%,-10.14 \%\right.$ to $-5.93 \%, \quad \mathrm{P}<0.001, \quad \mathrm{I}^{2}=0 \%$, 10 comparisons, 3238 participants), and bolus $\left(-9.14 \%,-12.17 \%\right.$ to $-6.12 \%, \mathrm{P}<0.001, \mathrm{I}^{2}=67 \%$, 10 comparisons, 3238 participants) insulin dose in patients with type 1 diabetes (supplementary figure 5). Heterogeneity for bolus insulin dose was high, and was accounted for by significant subgroup differences between high dose (400 mg/day) and low dose (200 $\mathrm{mg} /$ day) sotagliflozin (supplementary table 4).

\section{Urinary glucose excretion}

Pooled data came from two randomised controlled trials. $^{26}{ }^{28}$ They indicated that daily urinary glucose excretion progressively increased with increasing sotagliflozin dose from $75 \mathrm{mg} /$ day to $200 \mathrm{mg} /$ day, but then urinary glucose excretion reached a plateau at around $60 \mathrm{~g} /$ day with either $200 \mathrm{mg} /$ day and 400 $\mathrm{mg} /$ day of sotagliflozin (supplementary figure 6; supplementary table 4)

\section{Non-glycaemic outcomes Body weight}

Compared with controls, sotagliflozin induced a significant weight reduction (weighted mean difference $-3.54 \%, 95 \%$ confidence interval $-3.98 \%$ to $-3.09 \%$, $\mathrm{P}<0.001, \mathrm{I}^{2}=18 \%, 10$ comparisons, 3238 participants; fig 3). On meta-regression analysis, weight change (\%) correlated with the magnitude of total insulin dose reduction from baseline $(\beta=0.213 ; \mathrm{P}=0.001)$.

\section{Blood pressure}

Compared with placebo, sotagliflozin use was associated with a reduction in systolic blood pressure (weighted mean difference $-3.85 \mathrm{~mm} \mathrm{Hg}, 95 \%$ confidence interval -4.76 to $-2.93, \mathrm{P}<0.001, \mathrm{I}^{2}=0 \%$ ) and in diastolic blood pressure $(-1.43 \mathrm{~mm} \mathrm{Hg},-1.98$ to $-0.89, \mathrm{P}<0.001$, $\mathrm{I}^{2}=0 \%, 10$ comparisons, 3238 participants; fig 3$)$. These effects were not associated with an increased incidence of ortostatic hypotension (data not shown).

Renal effects: estimated glomerular filtration rate and urinary albumin:creatinine ratio

Compared with placebo, sotagliflozin treatment was associated with a slight reduction in eGFR (weighted mean difference $-0.80 \mathrm{~mL} / \mathrm{min} / 1.73 \mathrm{~m}^{2}$, 95\% confidence interval -1.42 to $-0.18, \mathrm{P}=0.01, \mathrm{I}^{2}=0 \%, 10$ comparisons, 3238 participants; fig 4). The reduction in eGFR occurred only with sotagliflozin at $200 \mathrm{mg} /$ day (fig 4; supplementary table 4). Subgroup analysis showed that the eGFR reduction was observed only in randomised controlled trials lasting 12 weeks or less, but not in trials of longer duration (supplementary table 3). Urinary ACR was evaluated in three phase III randomised controlled trials (2977 participants, with trial duration ranging 24-52 weeks, and mean baseline ACR of participants of 52.6, 31.6, $54.3 \mathrm{mg} / \mathrm{g}$, respectively). ${ }^{29-31}$ Pooled analysis of these trials showed that sotagliflozin was associated with a decrease in ACR (weighted mean difference $-14.57 \mathrm{mg} / \mathrm{g}$, 95\% confidence interval -2.28 to $-26.87, \mathrm{P}=0.02, \mathrm{I}^{2}=0 \%$, five comparisons; fig 4).

To gain further insight into the effect of time on renal function, we examined the effect of sotagliflozin on eGFR in the two longest trials (duration 52 weeks) during the initial 24 weeks and during the following 28 weeks. While sotagliflozin continued to reduce ACR throughout the treatment period, the difference in eGFR between sotagliflozin and placebo varied during follow-up. During the initial 24 weeks, patients receiving sotagliflozin showed a decline in eGFR, both in absolute terms and as compared with controls. But in the following 28 weeks, the trend was inverted and sotagliflozin induced a significant eGFR increase, both in absolute terms and as compared with controls (supplementary figure 7A-B).

\section{Plasma lipids}

No randomised controlled trial reported the effect of active treatment or placebo on low density lipoproteincholesterol, high density lipoprotein-cholesterol, or triglyceride.

\section{Safety outcomes}

Hypoglycaemia and severe hypoglycaemia

The definitions of hypoglycaemia and severe hypoglycaemia were consistent across all randomised controlled trials and in line with current guideline recommendations (supplementary text). Compared with placebo, sotagliflozin treatment was associated with a lower rate of hypoglycaemia events (weighted mean difference -9.09 events per patient year, 95\% confidence interval -13.82 to $-4.36, \mathrm{P}<0.001, \mathrm{I}^{2}=0 \%$, 10 comparisons, 3238 participants) and with a 31\% lower risk of severe hypoglycaemia (relative risk 0.69 , 0.49 to $0.98, \mathrm{P}=0.04,10$ comparisons, $\mathrm{I}^{2}=0 \%$; fig 5).

\section{Diabetic ketoacidosis}

Compared with placebo, sotagliflozin was associated with an increased risk of diabetic ketoacidosis (relative risk 3.93, 95\% confidence interval 1.94 to 7.96 , $\mathrm{P}<0.001 ; 10$ comparisons, $\mathrm{I}^{2}=0 \%, 3238$ participants, trial duration 4-52 weeks; fig 5). Forty six (69\%) of all cases of diabetic ketoacidosis occurred at blood glucose levels higher than $250 \mathrm{mg} / \mathrm{dL}$, while the remaining 21 (31\%) cases occurred with blood glucose values of 150$250 \mathrm{mg} / \mathrm{dL}$ (supplementary table 5). The risk for diabetic ketoacidosis was increased for patients on multiple daily injections $(3.22,1.24$ to $9.09, \mathrm{P}=0.01 ; 10$ comparisons, $\mathrm{I}^{2}=0 \%, 2072$ patients) as well as for patients on continuous subcutaneous infusion $(6.40,2.82$ to 15.64 , $\mathrm{P}<0.001 ; 10$ comparisons, $\mathrm{I}^{2}=0 \%, 1166$ patients). 


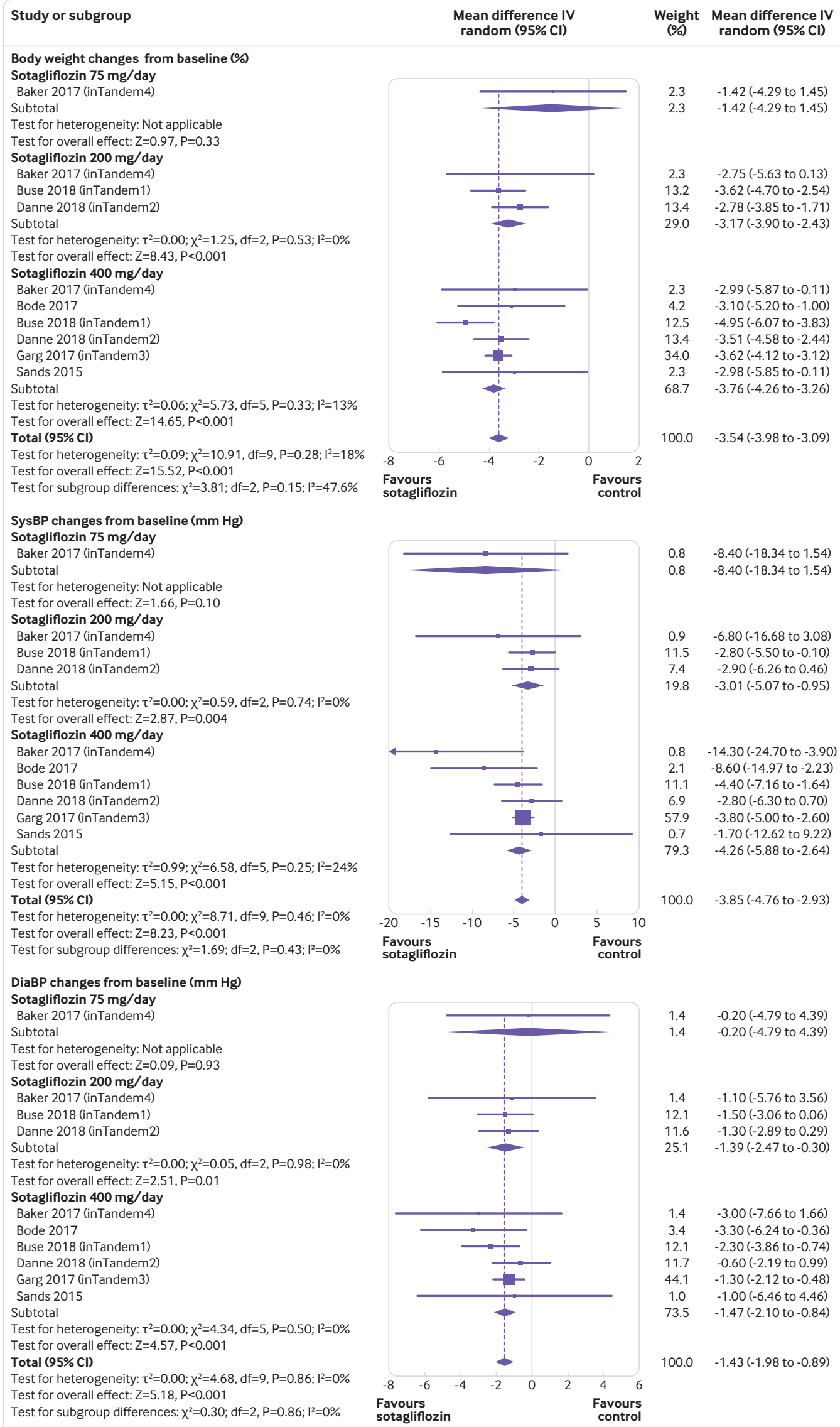

Fig 3 | Forest plot comparing effect of sotagliflozin versus placebo on body weight, systolic blood pressure (sysBP), and diastolic blood pressure (diaBP). IV=inverse invariance 


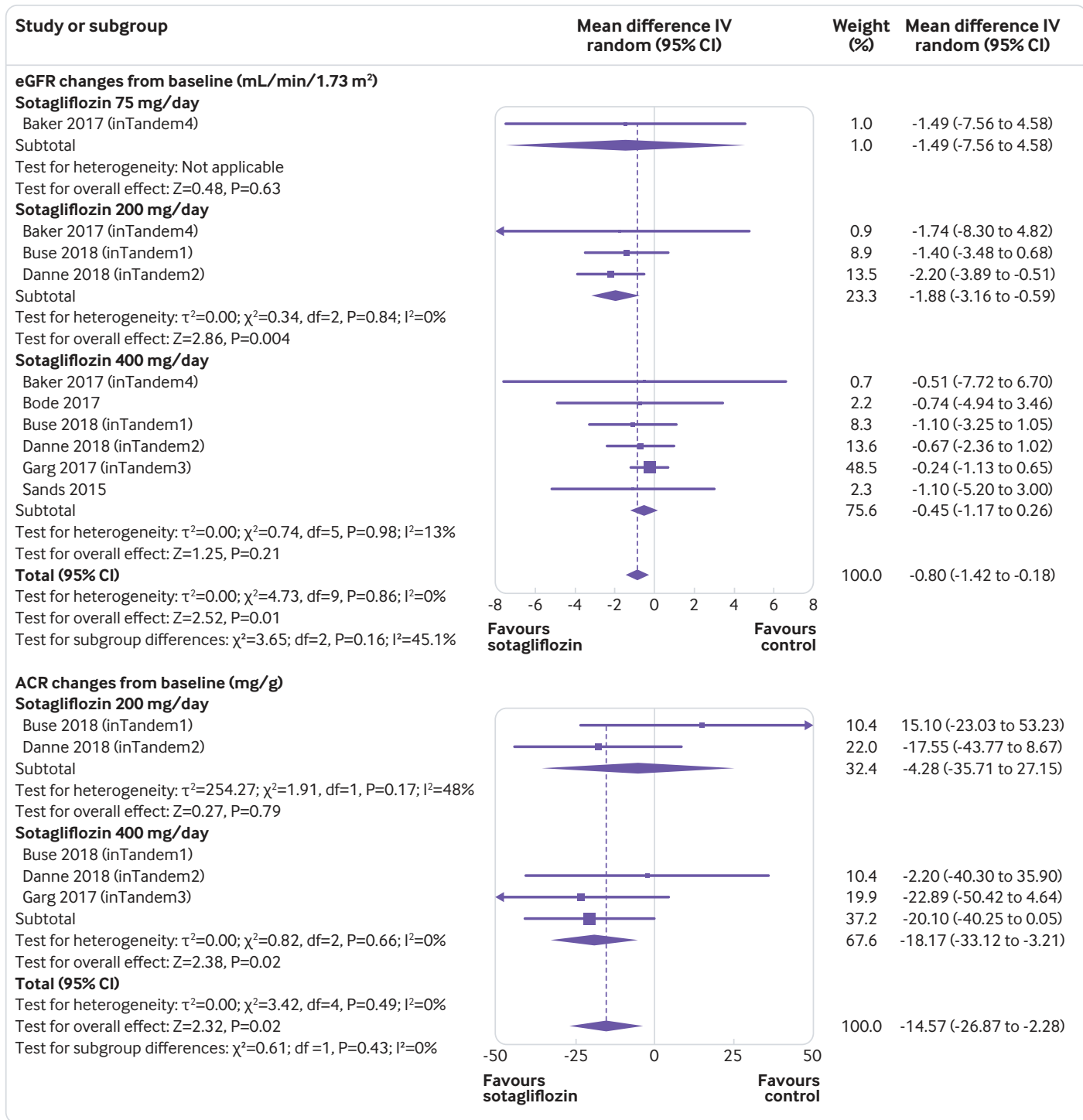

Fig 4 | Forest plot comparing effect of sotagliflozin versus placebo on estimated glomerular filtration rate (eGFR) and urinary albumin:creatinine ratio $(A C R)$. IV=inverse invariance

Subgroup analyses showed that the risk of diabetic ketoacidosis varied according to the initial $\mathrm{HbA1c}$ of included randomised controlled trials. The risk increased in trials with a mean initial HbA1c lower than $8 \%$ (relative risk $6.62,95 \%$ confidence interval 2.04 to $21.48, \mathrm{I}^{2}=0 \%, \mathrm{P}=0.002, \mathrm{n}=3$ trials, 1608 participants), but not in trials with a mean HbA1c of $8 \%$ or more $\left(2.21,0.43\right.$ to $11.42, \mathrm{I}^{2}=0 \%, \mathrm{P}=0.34$, $\mathrm{n}=3$ trials, 1630 participants; supplementary table 3). In a meta-regression model including sotagliflozin dose, trial duration, initial $\mathrm{HbA} 1 \mathrm{c}$, initial fasting plasma glucose, changes in HbA1c and fasting plasma glucose, total bolus and basal insulin doses (baseline, changes, and end-of-treatment doses), fasting and postprandial glycaemia, body weight changes, and volume depletion events, the risk of diabetic ketoacidosis correlated inversely with initial HbA1c $(\beta=-0.331 ; P=0.009)$ and with the magnitude of basal insulin dose reduction $(\beta=-0.218 ; \mathrm{P}=0.012$; supplementary figure 8).
Urinary tract infections and genital tract infections Compared with placebo, sotagliflozin did not affect the risk of urinary tract infections (relative risk 0.97 , 95\% confidence interval 0.71 to $1.33, \mathrm{P}=0.84 ; 10$ comparisons, $\mathrm{I}^{2}=0 \%, 3238$ participants) but was associated with an increased risk of mycotic genital tract infections $(3.12,2.14$ to $4.54, \mathrm{P}<0.001 ; 10$ comparisons, $\mathrm{I}^{2}=0 \%$; fig 6 ). In a meta-regression model, the risk of genital tract infection was not related to sotagliflozin dose, urinary glucose excretion, initial HbA1c, initial fasting plasma glucose, and changes in $\mathrm{HbA} 1 \mathrm{c}$ and fasting plasma glucose (all $\mathrm{P}>0.5$ ).

\section{Gastrointestinal events}

Compared with controls, sotagliflozin was associated with an increased risk of diarrhoea (relative risk 1.50, 95\% confidence interval 1.08 to 2.10 , $\mathrm{P}=0.02 ; 10$ comparisons, $\mathrm{I}^{2}=0 \%, 3238$ participants; supplementary figure 9A), but not of other gastrointestinal symptoms (supplementary table 5). 


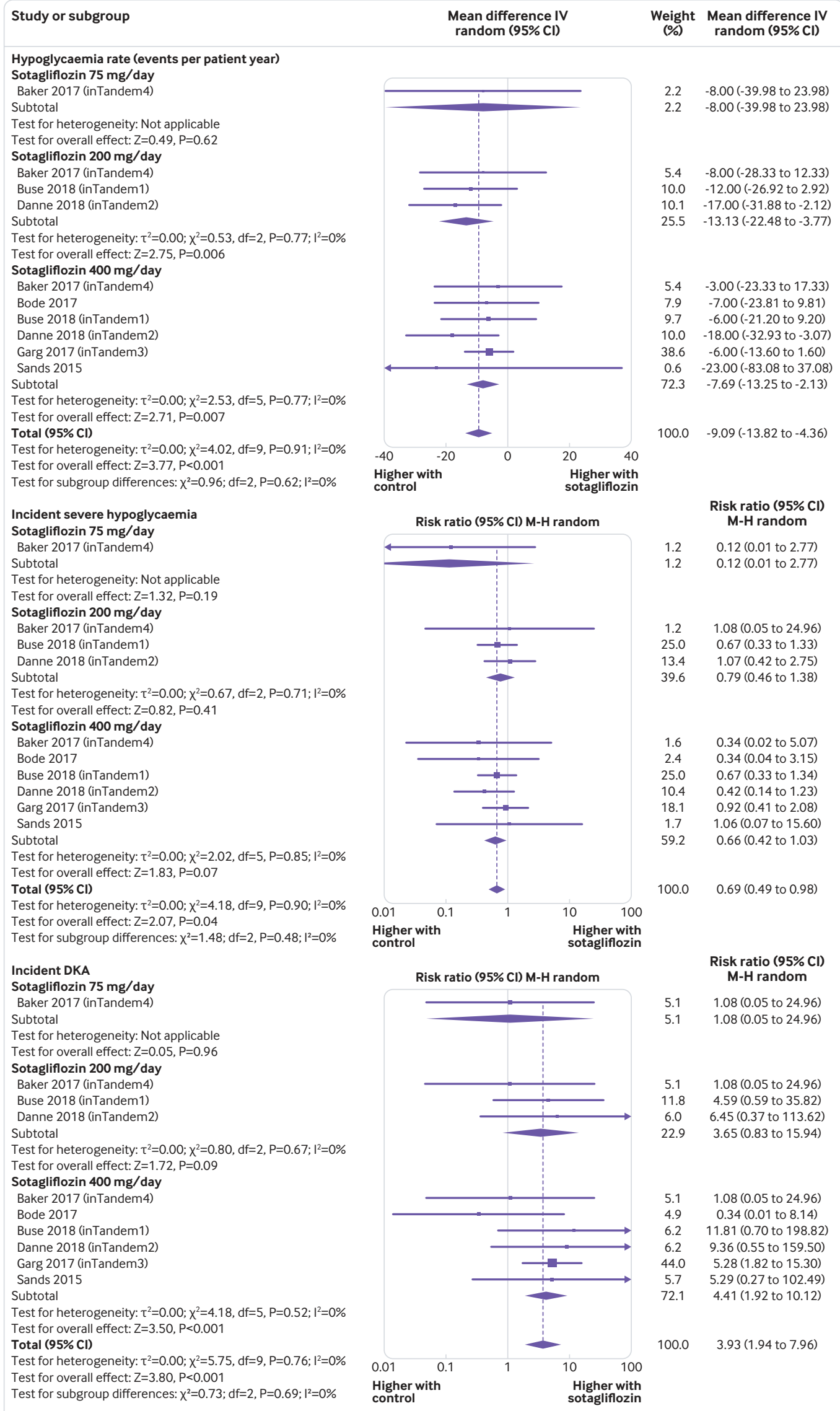

Fig 5 | Forest plot comparing effect of sotagliflozin versus placebo on hypoglycaemia, severe hypoglycaemia, and diabetic ketoacidosis (DKA). IV=inverse invariance; $M-H=$ Mantel-Haenszel 


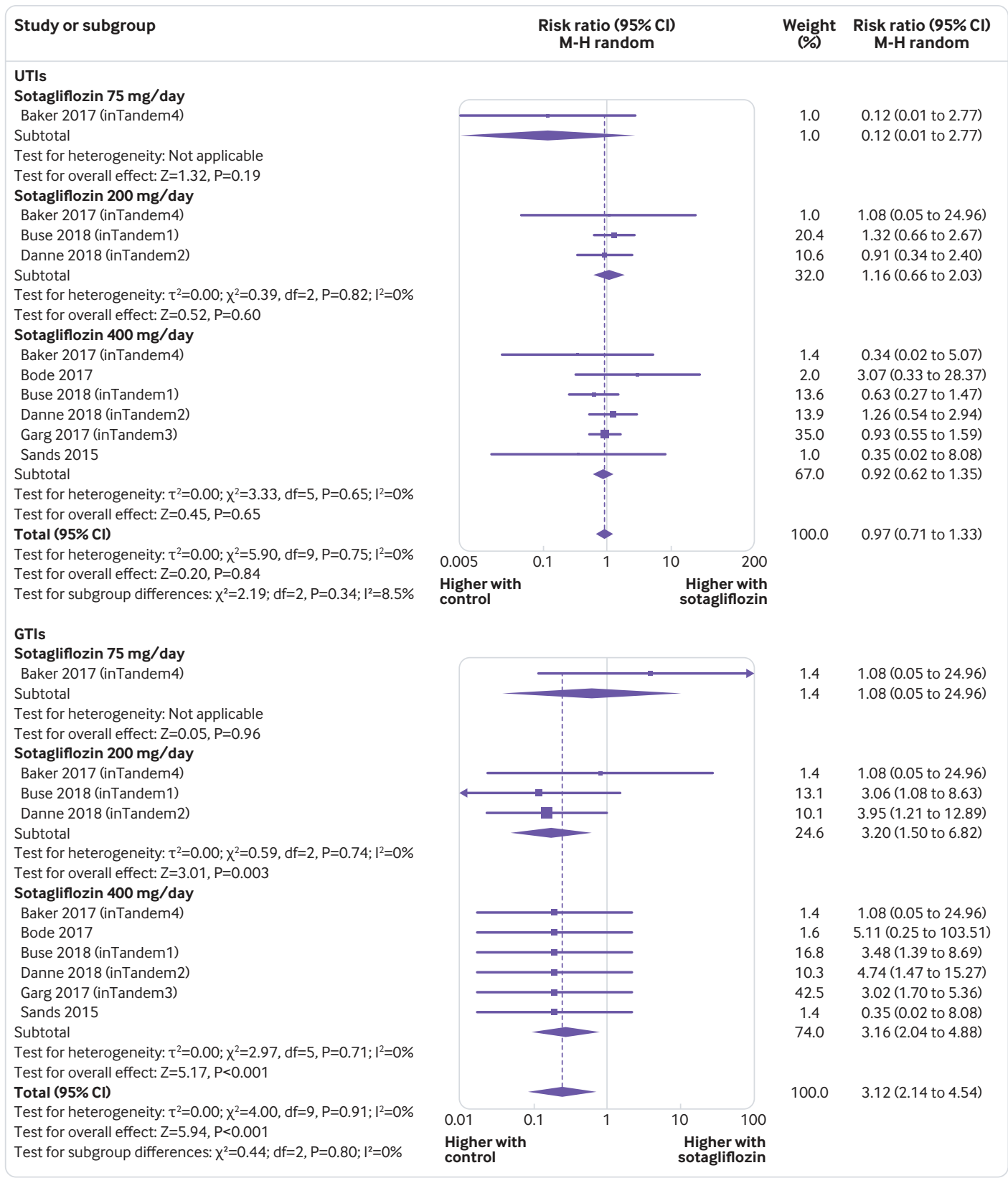

Fig 6 | Forest plot comparing effect of sotagliflozin versus placebo on urinary tract infection (UTI) and genital tract infection (GTI). $M-H=$ Mantel-Haenszel

\section{Other adverse events}

Compared with controls, sotagliflozin treatment was associated with an increased risk of acidosis related adverse events (relative risk 3.85, 95\% confidence interval 2.33 to $6.36, \mathrm{P}<0.001 ; 10$ comparisons, $\left.\mathrm{I}^{2}=0 \%\right)$ and volume depletion events $(2.19,1.10$ to $4.36, \quad \mathrm{P}=0.03 ; 10$ comparisons $=10, \mathrm{I}^{2}=0 \%$; supplementary figure 9B; supplementary figure 10A; supplementary table 5). Subgroup analysis revealed that the risk of volume depletion events was increased in the first 12 weeks of treatment, but then subsided (supplementary table 3 ). Sotagliflozin did not affect the risk of MACE (1.06, 0.40 to 2.82, $\mathrm{P}=0.91 ; 10$ comparisons, $\mathrm{I}^{2}=6 \%$ ), cancer (0.86, 0.25 to $2.97, \mathrm{P}=0.81$; nine comparisons,
$\left.\mathrm{I}^{2}=0 \%\right)$, or all cause death $(0.35,0.07$ to 1.71 , $\mathrm{P}=0.19$; nine comparisons, $\mathrm{I}^{2}=0 \%$; supplementary table 5; supplementary figure 10B). The effect of sotagliflozin on other adverse events is summarised in supplementary table 5 .

Adverse events leading to treatment discontinuation We then evaluated the proportion of patients experiencing each adverse event who discontinued treatment due to the adverse event. The most common adverse events leading to treatment discontinuation were diabetic ketoacidosis $(35.8 \%$ of all patients with diabetic ketoacidosis discontinued treatment), diarrhoea (6.9\%), genital tract infections (6.3\%), severe hypoglycaemia (5.6\%), urinary tract 
infections (4.4\%), and volume depletion events (4.3\%).

\section{Dose-response analysis}

We analysed dose-response interactions within the three randomised controlled trials that evaluated different sotagliflozin doses. One trial evaluated sotagliflozin 75 , 200 , and $400 \mathrm{mg} /$ day doses ${ }^{28}$ while two trials assessed the 200 and $400 \mathrm{mg} /$ daydoses $^{3031}$ (supplementary table 1). The $200 \mathrm{mg} /$ day dose had a greater glycosuric effect (urinary glucose excretion) than the $75 \mathrm{mg} /$ day dose (weighted mean difference $16.00 \mathrm{~g} / \mathrm{day}, 95 \%$ confidence interval 3.06 to 28.94), but this effect did not increase further with the $400 \mathrm{mg} /$ day dose $(13.00 \mathrm{~g} /$ day, -1.78 to 27.78; supplementary table 4).

Sotagliflozin $400 \mathrm{mg} /$ day was associated with a greater improvement than the $200 \mathrm{mg} /$ day dose in HbA1c (weighted mean difference $-0.22 \%$, 95\% confidence interval $-0.28 \%$ to $-0.12 \%$ ); fasting plasma glucose $(-9.82 \mathrm{mg} / \mathrm{dL},-17.05$ to -2.58$)$; 2h-PPG ( $-20.51 \mathrm{mg} / \mathrm{dL},-33.98$ to -7.03$)$; time in range $(6.48 \%, 2.97 \%$ to $9.99 \%)$; average daily glucose $(-11.02 \mathrm{mg} / \mathrm{dL},-17.70$ to -4.33$)$; daily total $(-5.25 \%$, $-7.66 \%$ to $-2.84 \%)$, basal $(-4.64 \%,-8.64 \%$ to $-0.64 \%)$, and bolus $(-7.85 \%,-11.96 \%$ to $-3.75 \%)$ insulin dose; body weight $(-0.96 \%,-1.55$ to -0.37$)$; systolic blood pressure $(-2.51 \mathrm{~mm} \mathrm{Hg},-3.83$ to -1.20$)$; eGFR (1.05 mL/min/1.73 $\mathrm{m}^{2}, 0.11$ to 22.12$)$; and ACR
(-12.29 mg/g, -26.81 to -1.23 ; supplementary table 4). We did not find any association between different sotagliflozin doses and adverse events. The results of the within-trial comparison were all confirmed by the across-trial approach.

\section{Sensitivity analyses}

Sensitivity analysis conducted by alternative pooling methods including Peto's odds ratio, which has a greater power at event rates below $1 \%,{ }^{54}$ confirmed the results of the main analysis (supplementary table 3 ).

\section{Grading of evidence}

Quality of evidence was downgraded to moderate for effect on time-in-range glucose, because it was unclear whether the population undergoing substudies of continuous glucose monitoring was representative of the whole study population (table 1). Quality of evidence was downgraded to low for MACE and all cause mortality because of imprecision (table 2).

\section{Discussion}

Our analysis had four main findings. Firstly, in patients with type 1 diabetes, sotagliflozin as add-on treatment to insulin ameliorated glycaemic efficacy outcomes and also showed non-glycaemic benefits, including body weight, blood pressure, and nephropathy marker reduction. Secondly, sotagliflozin treatment was

\begin{tabular}{|c|c|c|c|c|c|c|}
\hline \multirow[b]{2}{*}{ Outcomes and follow-up } & \multicolumn{2}{|c|}{ Anticipated absolute effects $(95 \% \mathrm{Cl}) \dagger$} & \multirow{2}{*}{$\begin{array}{l}\text { Relative effect } \\
(95 \% \mathrm{Cl})\end{array}$} & \multirow{2}{*}{$\begin{array}{l}\text { No of participants } \\
\text { (and RCTs) }\end{array}$} & \multirow{2}{*}{$\begin{array}{l}\text { Certainty of } \\
\text { evidence (GRADE) }\end{array}$} & \multirow{2}{*}{ Comments } \\
\hline & Risk with placebo & Risk with sotagliflozin & & & & \\
\hline \multicolumn{7}{|c|}{ Sotagliflozin v placebo for type 1 diabetes: glycaemic effect outcomes } \\
\hline $\begin{array}{l}\text { Mean change in } \mathrm{HbA} 1 \mathrm{c}(\%) \text {; } \\
\text { follow-up 4-52 weeks }\end{array}$ & $\begin{array}{l}\text { Mean change: ranged } \\
\text { from }-0.99 \% \text { to } \\
0.04 \%\end{array}$ & $\begin{array}{l}\text { Mean change in intervention } \\
\text { group: } 0.34 \%(0.41 \% \text { to } \\
0.27 \%) \text { lower }\end{array}$ & - & $3238(6)$ & High & $\begin{array}{l}\text { Large effect. Dose-response } \\
\text { gradient across 200-400 } \\
\mathrm{mg} / \text { day doses }\end{array}$ \\
\hline $\begin{array}{l}\text { Mean change in fasting plasma } \\
\text { glucose }(\mathrm{mg} / \mathrm{dL}) ; \\
\text { follow-up } 4-52 \text { weeks }\end{array}$ & $\begin{array}{l}\text { Mean change: ranged } \\
\text { from }-11 \text { to } 39 \\
\mathrm{mg} / \mathrm{dL}\end{array}$ & $\begin{array}{l}\text { Mean change in intervention } \\
\text { group: } 16.98 \mathrm{mg} / \mathrm{dL}(22.09 \\
\text { to } 11.86) \text { lower }\end{array}$ & - & $3238(6)$ & High & $\begin{array}{l}\text { Large effect. Dose-response } \\
\text { gradient across 200-400 } \\
\mathrm{mg} / \text { day doses }\end{array}$ \\
\hline $\begin{array}{l}\text { Mean change in } 2 \text { hour-post- } \\
\text { prandial plasma glucose (mg/ } \\
\mathrm{dL}) ; \text { follow-up } 4-52 \text { weeks }\end{array}$ & $\begin{array}{l}\text { Mean change: ranged } \\
\text { from }-18.5 \text { to } 0 \\
\mathrm{mg} / \mathrm{dL}\end{array}$ & $\begin{array}{l}\text { Mean change in intervention } \\
\text { group: } 39.24 \mathrm{mg} / \mathrm{dL}(50.42 \\
\text { to } 28.06) \text { lower }\end{array}$ & - & $539(5)$ & High & $\begin{array}{l}\text { Large effect. Dose-response } \\
\text { gradient across 200-400 } \\
\mathrm{mg} / \text { day doses }\end{array}$ \\
\hline $\begin{array}{l}\text { Mean change of time in range } \\
(\% ; 70-180 \mathrm{mg} / \mathrm{dL}) ; \text { follow-up } \\
\text { 4-52 weeks }\end{array}$ & $\begin{array}{l}\text { Mean change: ranged } \\
\text { from }-1.83 \% \text { to } \\
-0.2 \%\end{array}$ & $\begin{array}{l}\text { Mean change in intervention } \\
\text { group: } 9.73 \%(6.66 \% \text { to } \\
12.81 \%) \text { higher }\end{array}$ & - & 398 (4) & Moderateł & $\begin{array}{l}\text { Large effect. Dose-response } \\
\text { gradient across 200-400 } \\
\mathrm{mg} / \text { day doses }\end{array}$ \\
\hline \multicolumn{7}{|c|}{ Sotagliflozin v placebo for type 1 diabetes: non-glycaemic effect outcomes } \\
\hline $\begin{array}{l}\text { Mean change in body weight (\%); } \\
\text { follow-up 4-52 weeks }\end{array}$ & $\begin{array}{l}\text { Mean change: ranged } \\
\text { from }-0.99 \text { to } 0.04 \%\end{array}$ & $\begin{array}{l}\text { Mean change in intervention } \\
\text { group: } 3.54 \%(3.98 \% \text { to } \\
3.09 \%) \text { lower }\end{array}$ & - & $3238(6)$ & High & $\begin{array}{l}\text { Dose-response gradient } \\
\text { across } 200-400 \mathrm{mg} / \text { day } \\
\text { doses }\end{array}$ \\
\hline $\begin{array}{l}\text { Mean change in systolic blood } \\
\text { pressure }(\mathrm{mm} \mathrm{Hg}) ; \text { follow-up } \\
\text { 4-52 weeks }\end{array}$ & $\begin{array}{l}\text { Mean change: ranged } \\
\text { from }-3.8 \text { to } 1.7 \\
\mathrm{~mm} \mathrm{Hg}\end{array}$ & $\begin{array}{l}\text { Mean change in intervention } \\
\text { group: } 3.85 \mathrm{~mm} \mathrm{Hg} \text { ( } 4.76 \text { to } \\
2.93 \text { ) lower }\end{array}$ & - & $3238(6)$ & High & $\begin{array}{l}\text { Dose-response gradient } \\
\text { across } 200-400 \mathrm{mg} / \text { day } \\
\text { doses }\end{array}$ \\
\hline $\begin{array}{l}\text { Mean change in eGFR (mL/ } \\
\left.\text { min } / 1.73 \mathrm{~m}^{2}\right) ; \text { follow-up } 4-52 \\
\text { weeks }\end{array}$ & $\begin{array}{l}\text { Mean change: ranged } \\
\text { from }-1.09 \text { to } 0.34 \\
\mathrm{~mL} / \mathrm{min} / 1.73^{\mathrm{m}} 2\end{array}$ & $\begin{array}{l}\text { Mean change in intervention } \\
\text { group: } 0.8 \mathrm{~mL} / \mathrm{min} / 1.73 \mathrm{~m}^{2} \\
\text { (1.42 to } 0.18 \text { ) lower }\end{array}$ & - & $3238(6)$ & High & $\begin{array}{l}\text { Dose-response gradient } \\
\text { across } 200-400 \mathrm{mg} / \text { day } \\
\text { doses }\end{array}$ \\
\hline $\begin{array}{l}\text { Mean change in urinary ACR } \\
\text { (mg/g); follow-up: range } 24 \\
\text { weeks to } 52 \text { weeks }\end{array}$ & $\begin{array}{l}\text { Mean change: ranged } \\
\text { from } 4.1 \text { to } 14.9 \\
\mathrm{mg} / \mathrm{g}\end{array}$ & $\begin{array}{l}\text { Mean change in intervention } \\
\text { group: } 14.57 \mathrm{mg} / \mathrm{g}(26.87 \\
\text { to } 2.28) \text { lower }\end{array}$ & - & 2977 (3) & High & $\begin{array}{l}\text { Dose-response gradient } \\
\text { across } 200-400 \mathrm{mg} / \text { day } \\
\text { doses }\end{array}$ \\
\hline
\end{tabular}

$1 \mathrm{mg} / \mathrm{dL}=0.0555 \mathrm{mmol} / \mathrm{L}$.

GRADE=grading of recommendations assessment, development, and evaluation; $R C T=$ randomised controlled trial; eGFR=estimated glomerular filtration rate: $A C R=a l b u m i n$ creatinine ratio. *GRADE working group grades of evidence: high certainty (very confident that the true effect lies close to that of the estimate of the effect); moderate certainty (moderately confident in the effect estimate; the true effect is likely to be close to the estimate of the effect, but there is a possibility that it is substantially different); low certainty (confidence in the effect estimate is limited; the true effect could be substantially different from the estimate of the effect); very low certainty (very little confidence in the effect estimate; the true effect is likely to be substantially different from the estimate of effect).

tRisk (95\% confidence interval) in the intervention group is based on the assumed risk in the comparison group and the relative effect ( $95 \%$ confidence interval) of the intervention.

fUnclear whether the population undergoing continuous glucose monitoring substudies was representative of the whole trial population in the inTandem 1 and inTandem 2 trials. For calculation of the optimal information size, $a=0.05$ and $\beta=0.2$ was used. 


\begin{tabular}{|c|c|c|c|c|c|c|}
\hline \multirow[b]{2}{*}{ Outcomes and follow-up } & \multicolumn{2}{|c|}{ Anticipated absolute effects $(95 \% \mathrm{Cl}) \dagger$} & \multirow{2}{*}{$\begin{array}{l}\text { Risk ratio } \\
(95 \% \mathrm{Cl})\end{array}$} & \multirow{2}{*}{$\begin{array}{l}\text { No of participants } \\
\text { (and RCTs) }\end{array}$} & \multirow{2}{*}{$\begin{array}{l}\text { Certainty of evi- } \\
\text { dence (GRADE) }\end{array}$} & \multirow[b]{2}{*}{ Comments } \\
\hline & Risk with placebo & Risk with sotagliflozin & & & & \\
\hline $\begin{array}{l}\text { Mean change in hypoglycaemia } \\
\text { events (events per patient year); } \\
\text { follow-up 4-52 weeks }\end{array}$ & $\begin{array}{l}\text { Mean change: ranged } \\
\text { from } 69 \text { to } 179 \text { events } \\
\text { per patient year }\end{array}$ & $\begin{array}{l}\text { Mean change in intervention } \\
\text { group: } 9.09 \text { events per patient } \\
\text { year ( } 13.82 \text { to } 4.36 \text { ) lower }\end{array}$ & - & $3238(6)$ & High & - \\
\hline $\begin{array}{l}\text { Incidence of severe hypoglycae- } \\
\text { mia; follow-up 4-52 weeks }\end{array}$ & 43 per 1000 & 30 per 1000 (21 to 42$)$ & 0.69 (0.49 to 0.98$)$ & $3238(6)$ & High & - \\
\hline $\begin{array}{l}\text { Incidence of diabetic ketoacido- } \\
\text { sis; follow-up 4-52 weeks }\end{array}$ & 5 per 1000 & 18 per 1000 (9 to 36$)$ & $3.93(1.94$ to 7.96$)$ & $3238(6)$ & High & Large effect \\
\hline $\begin{array}{l}\text { Incidence of urinary tract infec- } \\
\text { tions; follow-up 4-52 weeks }\end{array}$ & 48 per 1000 & 46 per 1000 (34 to 63 ) & $0.97(0.71$ to 1.33$)$ & $3238(6)$ & High & - \\
\hline $\begin{array}{l}\text { Incidence of genital tract infec- } \\
\text { tions; follow-up 4-52 weeks }\end{array}$ & 23 per 1000 & 73 per 1000 (50 to 106$)$ & $3.12(2.14$ to 4.54$)$ & $3238(6)$ & High & Large effect \\
\hline $\begin{array}{l}\text { Incidence of diarrhoea; follow-up } \\
\text { 4-52 weeks }\end{array}$ & 35 per 1000 & 52 per 1000 (37 to 73 ) & 1.50 (1.08 to 2.10$)$ & $3238(6)$ & High & - \\
\hline $\begin{array}{l}\text { Incidence of adverse events lead- } \\
\text { ing to treatment discontinuation; } \\
\text { follow-up 4-52 weeks }\end{array}$ & 23 per 1000 & 31 per 1000 (18 to 54$)$ & $1.34(0.78$ to 2.30$)$ & $3238(6)$ & High & - \\
\hline $\begin{array}{l}\text { Incidence of serious adverse } \\
\text { events; follow-up 4-52 weeks }\end{array}$ & 69 per 1000 & 76 per 1.000 (58 to 99$)$ & $1.11(0.85$ to 1.44$)$ & $3238(6)$ & High & - \\
\hline $\begin{array}{l}\text { Incidence of major adverse } \\
\text { cardiovascular events; follow-up: } \\
\text { 4-52 weeks }\end{array}$ & 5 per 1000 & 6 per 1000 (2 to 15$)$ & $1.06(0.40$ to 2.82$)$ & $3238(6)$ & Low & $\begin{array}{l}\text { Few events, OIS } \\
\text { not reached }\end{array}$ \\
\hline $\begin{array}{l}\text { All cause mortality; follow-up } \\
\text { 4-52 weeks }\end{array}$ & 2 per 1000 & 1 per 1000 (0 to 4) & $0.34(0.07$ to 1.70$)$ & $3238(6)$ & Low $\ddagger$ & $\begin{array}{l}\text { Few events, OIS } \\
\text { not reached }\end{array}$ \\
\hline
\end{tabular}

GRADE=grading of recommendations assessment, development, and evaluation; RCT=randomised controlled trial; OIS=optimal information size

*GRADE working group grades of evidence: high certainty (very confident that the true effect lies close to that of the estimate of the effect); moderate certainty (moderately confident in the effect estimate; the true effect is likely to be close to the estimate of the effect, but there is a possibility that it is substantially different); low certainty (confidence in the effect estimate is limited; the true effect could be substantially different from the estimate of the effect); very low certainty (very little confidence in the effect estimate; the true effect is likely to be substantially different from the estimate of effect).

tRisk ( $95 \%$ confidence interval) in the intervention group is based on the assumed risk in the comparison group and the relative effect ( $95 \%$ confidence interval) of the intervention.

$\neq$ Downgraded for imprecision. For calculation of the OIS, $a=0.05$ and $\beta=0.2$ was used.

associated with a significant reduction in the incidence of hypoglycaemia and severe hypoglycaemia. Thirdly, diabetic ketoacidosis was the most serious and frequent adverse event associated with sotagliflozin treatment, which also increased the risk of genital tract infections, diarrhoea, and volume depletion events, but not of urinary tract infections. Finally, the risk of diabetic ketoacidosis varied depending on initial $\mathrm{HbA1c}$ levels and basal insulin dose reduction.

Of patients with type 1 diabetes, 30\% achieve glycaemic goals, up to $20 \%$ have severe hypoglycaemia every year, and $40 \%$ are overweight, ${ }^{3}$ hence urgently needing adjunctive treatment strategies to complement the glucose lowering effects of insulin and mitigate its unwanted effects. Hypoglycaemia, which results from the total dependence of patients with type 1 diabetes on injected insulin, is of particular concern and can be viewed as the highest unmet need in this population, ${ }^{910}$ because it is the main factor limiting optimal glucose control. Furthermore, severe hypoglycaemia is a strong predictor of adverse clinical outcomes and death in patients with diabetes. ${ }^{7-1860}$

None of the drugs recently approved for type 2 diabetes and seeking an indication for type 1 diabetes (including incretin analogues and SGLT2 inhibitors) reduced hypoglycaemic risk, which is either unaffected or increased by these treatments. ${ }^{22} 6162$ Several mechanisms could underlie the hypoglycaemic risk reduction observed with sotagliflozin. The dual intestinal SGLT1 and renal SGLT2 inhibition blunts acute glucose fluctuations and reduces glycaemic variability (supplementary figure 4C-D), thereby limiting the need for bolus insulin correction doses and the attendant hypoglycaemic risk (supplementary figure 5C). ${ }^{15} 1663$ The reduction in the rate of hypoglycaemic events could have itself contributed to reduce severe hypoglycaemia. The recurrence of hypoglycaemic episodes blunts autonomic and hormonal responses to subsequent hypoglycaemia, impairs hypoglycaemia awareness and glucose counter-regulation, and paves the way to severe hypoglycaemia. This functional impairment in counterregulatory mechanisms is distinct from autonomic neuropathy, occurs in the short term, and can be rapidly reversed by reducing hypoglycaemia recurrence. ${ }^{64}$

The analysis of pooled results from phase III randomised controlled trials also showed potential renoprotection for sotagliflozin, which reduced microalbuminuria, a marker of early diabetic nephropathy and an independent cardiovascular risk factor (fig 4). ${ }^{19}$ The transient eGFR decline observed in the initial 12 weeks of treatment is similar to that observed with other SGLT2 inhibitors ${ }^{65}$ and is consistent with renoprotective mechanisms of SGLT2 inhibition, which enhance afferent arteriolar tone, reduce intraglomerular pressure, and relieve glomerular hyperfiltration and barrier damage. ${ }^{66}$ However, in patients receiving sotagliflozin, the reduced glomerular perfusion could be aggravated by volume depletion favoured by concomitant osmotic glycosuria (due to renal SGLT2 inhibition) and diarrhoea (induced by intestinal SGLT1 inhibition; supplementary figure 9). Hence, volume depletion should be avoided in the early months of sotagliflozin treatment. 
By contrast with SGLT2 inhibitors, sotagliflozin did not increase the risk of urinary tract infections (fig 6). The reduced glycosuric effects of sotagliflozin as compared with SGLT2 inhibitors ${ }^{62}$ could have limited the incidence of urinary tract infections, while SGLT1 mediated intestinal glucose malabsorption could have increased diarrhoea, usually mild, thereby self limiting and not inducing treatment discontinuation.

Further supporting the relevance of intestinal SGLT1 inhibition, a dose-response gradient for most glycaemic outcomes was observed with increasing sotagliflozin dose, not paralleled by an increase in glycosuria, which reached a plateau at $60 \mathrm{~g} / \mathrm{day}$, 40$50 \%$ lower than that reported with full dose SGLT2 inhibitors $^{67}{ }^{68}$ (supplementary figure 6). Whether sotagliflozin maintains unaltered glucose lowering efficacy in the presence of moderate-to-severe renal failure will be assessed by ongoing trials in type 2 diabetes (supplementary table 2).

Diabetic ketoacidosis was the most common relevant adverse event, observed in 61 (3.1\%) of 1912 sotagliflozin treated patients and inducing treatment discontinuation in 38\% (supplementary table 5). While SGLT2 inhibitor associated diabetic ketoacidosis has been reported to occur often at uncharacteristically normal or mildly elevated levels $(<250 \mathrm{mg} / \mathrm{dL})$ of blood glucose (euglycaemic diabetic ketoacidosis), ${ }^{69}$ over two thirds of occurrences of sotagliflozin related diabetic ketoacidosis happened at high blood glucose levels (supplementary table 5). Notably, our data indicate that a lower initial $\mathrm{HbA} 1 \mathrm{c}$ and a greater reduction in basal insulin dose during sotagliflozin treatment could increase the risk for diabetic ketoacidosis (supplementary figure 8; supplementary table 3), possibly because patients with less deteriorated baseline glycaemic control experienced a more rapid down-titration of insulin dose with sotagliflozin. The extent of basal insulin down-titration seems central for diabetic ketoacidosis development by allowing unrestricted fasting induced lipolysis and ketogenesis on a background of negative glucose balance. ${ }^{69}$ Consistently, insulin dose reduction of more than $20 \%$ has been found to increase ketone levels and diminish the glucose lowering effect of SGLT2 inhibitors. ${ }^{70}$

\section{Clinical and policy implications}

Sotagliflozin treatment for up to 52 weeks provides consistent glycaemic and non-glycaemic benefits in patients with type 1 diabetes, including the reduction of unwanted effects of insulin treatment (that is, weight gain and hypoglycaemia). These effects make sotagliflozin an attractive adjunctive treatment to insulin in patients with type 1 diabetes, of whom $30 \%$ achieve target glycaemic goals, $40 \%$ are overweight, and up to $20 \%$ per year experience severe hypoglycaemia. ${ }^{3}$ The clinical impact of these benefits might be more appreciable in patients at higher risk of severe hypoglycaemia, such as those with recurrent hypoglycaemia and hypoglycaemia unawareness, who represent $17-36 \%$ of the general population with type 1 diabetes. ${ }^{71}$
Our analysis could also help minimise the risk of diabetic ketoacidosis in type 1 diabetes treated with sotagliflozin by appropriate patient selection and by defining appropriate protocols for basal insulin dose adjustment. Ketone testing should be performed after each basal insulin dose reduction, rather than relying solely on overt triggering conditions or symptoms of diabetic ketoacidosis, ${ }^{28-31}$ which often fail to recognise early diabetic ketoacidosis. ${ }^{72}$ Future research should define safer protocols for basal insulin dose adjustment. For example, in a recent phase III randomised controlled trial with dapagliflozin that reported no increased risk of diabetic ketoacidosis, participants were instructed to reduce insulin doses by no more than $20 \%$ on treatment initiation, to measure ketonaemia whenever glucose readings were consistently elevated, and then subsequently to uptitrate insulin doses back to baseline after positive ketone testing. ${ }^{73}$

\section{Strengths and limitations}

Strengths and limitations of our analysis come from the characteristics of included evidence. Strengths include the thorough assessment of efficacy and safety outcomes, and the direct impact of extracted evidence regarding relevant clinical outcomes (such as hypoglycaemia and diabetic ketoacidosis) on decision making in the management of type 1 diabetes. Limitations include the relatively small number and short duration of included trials (not exceeding 52 weeks), which prevented robust assessment of long term hard outcomes such as MACE and overall mortality. Furthermore, although all included randomised controlled trials had good methodological quality, $66 \%$ were industry funded, which could make them liable to sponsorship bias. ${ }^{45}$ Recent guidelines recommend against automatically downgrading industry funded trials and we therefore address this issue by verifying a list of items empirically linked by recent literature to biased outcomes in industry funded trials. ${ }^{43}$

We thank Richard D Riley for his valuable statistical advice.

Contributors: GM contributed to the data collection and elaboration, statistical analysis, writing and approval of manuscript; and is guarantor of the article. RG and MC contributed to the data collection and discussion, review of the manuscript, and approval of the manuscript. EP contributed to the data collection and discussion, and writing and approval of manuscript. The corresponding author attests that all listed authors meet authorship criteria and that no others meeting the criteria have been omitted.

Funding: This work received no funding

Competing interests: All authors have completed the ICMJE uniform disclosure form at www.icmje.org/coi_disclosure.pdf and declare: no support from any organisation for the submitted work; no financial relationships with any organisations that might have an interest in the submitted work in the previous three years; no other relationships or activities that could appear to have influenced the submitted work.

Ethical approval: The protocol of the meta-analysis was internally peer reviewed at Humanitas University Gradenigo Hospital's institutional review board and is available at our institution at request to the corresponding author.

Data sharing: The datasets used or analysed during the current study are available from the corresponding author on reasonable request.

The lead author affirms that the manuscript is an honest, accurate, and transparent account of the study being reported; that no important aspects of the study have been omitted; and that any 
discrepancies from the study as planned (and, if relevant, registered) have been explained.

This is an Open Access article distributed in accordance with the Creative Commons Attribution Non Commercial (CC BY-NC 4.0) license, which permits others to distribute, remix, adapt, build upon this work non-commercially, and license their derivative works on different terms, provided the original work is properly cited and the use is non commercial. See: http://creativecommons.org/licenses/by-nc/4.0/.

1 US Center for Disease Control and Prevention. 2019. https://www. cdc.gov/diabetes/library/socialmedia/infographics.html.

2 Turner R, Stratton I, Horton V, et al, UK Prospective Diabetes Study Group. UKPDS 25: autoantibodies to islet-cell cytoplasm and glutamic acid decarboxylase for prediction of insulin requirement in type 2 diabetes. Lancet 1997;350:1288-93. doi:10.1016/S01406736(97)03062-6

3 Miller KM, Foster NC, Beck RW, et al, T1D Exchange Clinic Network. Current state of type 1 diabetes treatment in the US: updated data from the T1D Exchange clinic registry. Diabetes Care 2015;38:971-8. doi:10.2337/dc15-0078

4 Lind M, Svensson AM, Kosiborod M, et al. Glycemic control and excess mortality in type 1 diabetes. N Engl I Med 2014;371:197282. doi:10.1056/NEJMoa1408214

5 Nathan DMDCCT/EDIC Research Group. The diabetes control and complications trial/epidemiology of diabetes interventions and complications study at 30 years: overview. Diabetes Care 2014;37:916. doi: $10.2337 /$ dc $13-2112$

6 American Diabetes Association. 8. Pharmacologic approaches to glycemic treatment: Standards of medical care in diabetes-2018. Diabetes Care 2018;41(Suppl 1):S73-85. doi:10.2337/ dc18-S008

7 Gerstein HC, Miller ME, Byington RP, et al, Action to Control Cardiovascular Risk in Diabetes Study Group. Effects of intensive glucose lowering in type 2 diabetes. N Engl / Med 2008;358:254559. doi:10.1056/NEIMoa0802743

8 Zoungas S, Patel A, Chalmers J, et al, ADVANCE Collaborative Group. Severe hypoglycemia and risks of vascular events and death. N Engl J Med 2010:363:1410-8. doi:10.1056/NEJMoa1003795

9 Seaquist ER, Anderson J, Childs B, et al. Hypoglycemia and diabetes: a report of a workgroup of the American Diabetes Association and the Endocrine Society. Diabetes Care 2013;36:1384-95. doi:10.2337/dc12-2480

10 Cefalu WT, Tamborlane WV, Skyler JS. Type 1 diabetes at a crossroads!Diabetes Care 2015;38:968-70. doi:10.2337/dc150615

11 Monnier L, Colette C, Owens D. The glycemic triumvirate and diabetic complications: is the whole greater than the sum of its component parts?Diabetes Res Clin Pract 2012;95:303-11. doi:10.1016/j. diabres.2011.10.014

12 Ceriello A, Esposito K, Piconi L, et al. Oscillating glucose is more deleterious to endothelial function and oxidative stress than mean glucose in normal and type 2 diabetic patients. Diabetes 2008;57:1349-54. doi:10.2337/db08-0063

13 Šoupal J, Škrha JJr, Fajmon M, et al. Glycemic variability is higher in type 1 diabetes patients with microvascular complications irrespective of glycemic control. Diabetes Technol Ther 2014;16:198203. doi:10.1089/dia.2013.0205

14 Snell-Bergeon JK, Roman R, Rodbard D, et al. Glycaemic variability is associated with coronary artery calcium in men with type 1 diabetes: the Coronary Artery Calcification in Type 1 Diabetes study. Diabet Med 2010;27:1436-42. doi:10.1111/j.1464-5491.2010.03127.x

15 Zinman B, Marso SP, Poulter NR, et al, DEVOTE Study Group. Dayto-day fasting glycaemic variability in DEVOTE: associations with severe hypoglycaemia and cardiovascular outcomes (DEVOTE 2). Diabetologia 2018;61:48-57. doi:10.1007/s00125-017-4423-z

16 Pieber TR, Marso SP, McGuire DK, et al, DEVOTE Study Group. DEVOTE 3: temporal relationships between severe hypoglycaemia, cardiovascular outcomes and mortality. Diabetologia 2018;61:5865. doi:10.1007/s00125-017-4422-0

17 Wright LA, Hirsch IB. Metrics beyond hemoglobin A1C in diabetes management: time in range, hypoglycemia, and other parameters. Diabetes Technol Ther 2017;19(S2):S16-26. doi:10.1089/ dia.2017.0029

18 Danne T, Nimri R, Battelino T, et al. International consensus on use of continuous glucose monitoring. Diabetes Care 2017:40:1631-40. doi:10.2337/dc17-1600

19 Davies MJ, D’Alessio DA, Fradkin J, et al. Management of hyperglycemia in type 2 diabetes, 2018. A consensus report by the American Diabetes Association (ADA) and the European Association for the Study of Diabetes (EASD). Diabetes Care 2018;41:2669-701. doi: $10.2337 /$ dci18-0033

20 American Diabetes Association. 6. Glycemic targets: Standards of medical care in diabetes-2018. Diabetes Care 2018;41(Suppl 1):S55-64. doi:10.2337/dc18-S006
21 Seidelmann SB, Feofanova E, Yu B, et al. Genetic variants in SGLT1, glucose tolerance, and cardiometabolic risk. I Am Coll Cardiol 2018:72:1763-73. doi:10.1016/j.jacc.2018.07.061

22 Yamada T, Shojima N, Noma H, Yamauchi T, Kadowaki T. Sodiumglucose co-transporter-2 inhibitors as add-on therapy to insulin for type 1 diabetes mellitus: systematic review and meta-analysis of randomized controlled trials. Diabetes Obevs Metab 2018;20:175561. doi:10.1111/dom.13260

23 Powell DR, DaCosta CM, Smith M, et al. Effect of LX4211 on glucose homeostasis and body composition in preclinical models. J Pharmacol Exp Ther 2014;350:232-42. doi:10.1124/ pet.114.214304

24 Powell DR, Smith M, Greer J, et al. LX4211 increases serum glucagon-like peptide 1 and peptide YY levels by reducing sodium/ glucose cotransporter 1 (SGLT1)-mediated absorption of intestinal glucose. / Pharmacol Exp Ther 2013;345:250-9. doi:10.1124/ jpet.113.203364

25 Meek TH, Dorfman MD, Matsen ME, et al. Evidence that in uncontrolled diabetes, hyperglucagonemia is required for ketosis but not for increased hepatic glucose production or hyperglycemia. Diabetes 2015;64:2376-87. doi:10.2337/db14-1562

26 Sands AT, Zambrowicz BP, Rosenstock J, et al. Sotagliflozin, a dual SGLT1 and SGLT2 inhibitor, as adjunct therapy to insulin in type 1 diabetes. Diabetes Care 2015;38:1181-8. doi:10.2337/dc14-2806

27 Bode B, Banks P, Strumph P, Sawhney S. The Sotagliflozin JDRF Study Writing Group. Efficacy and safety of sotagliflozin, a dual SGLT1 and SGLT2 inhibitor, as adjunct to insulin in young adults with poorly controlled type 1 diabetes (JDRF Study). Diabetologia 2017;60:S87-8.

28 Baker C, Wason S, Banks P. A 12-week dose-ranging study of sotagliflozin, a dual SGLT1 and SGLT2 inhibitor, as adjunct therapy to insulin in type 1 diabetes (inTandem4). Diabetologia 2017;60:S409.

29 Garg SK, Henry RR, Banks P, et al. Effects of sotagliflozin added to insulin in patients with type 1 diabetes. N Engl Med 2017;377:2337-48. doi:10.1056/NEJMoa1708337

30 Buse JB, Garg SK, Rosenstock J, et al. Sotagliflozin in combination with optimized insulin therapy in adults with type 1 diabetes: the North American inTandem1 Study. Diabetes Care 2018;41:1970-80. doi:10.2337/dc18-0343

31 Danne T, Cariou B, Banks P, et al. HbA and hypoglycemia reductions at 24 and 52 weeks with sotagliflozin in combination with insulin in adults with type 1 diabetes: the European inTandem2 Study. Diabetes Care 2018;41:1981-90. doi:10.2337/dc18-0342.

32 US Food and Drug Administration. Search results for sotagliflozin. https://search.usa.gov/search?utf8=\%E2\%9C\%93\&affiliate= fda\&query=sotagliflozin\&commit=Search

33 European Medicines Agency. Search results for sotagliflozin. https://www.ema.europa.eu/en/search/search?search_api_views fulltext=sotagliflozin

34 Pharmaceutical and Medical Devices Agency. Search results for sotagliflozin. https://ss.pmda.go.jp/en_all/ search. $x ? q=$ sotagliflozin\&ie=UTF-8\&page $=1 \& x=30 \& y=11$

35 Lexicon Pharmaceuticals. Homepage. 2019. www.lexpharma.com

36 Sanofi. Homepage. 2019. https://www.sanofi.com

37 Esposito K, Giugliano D, Nappo F, Marfella RCampanian Postprandial Hyperglycemia Study Group. Regression of carotid atherosclerosis by control of postprandial hyperglycemia in type 2 diabetes mellitus. Circulation 2004;110:214-9. doi:10.1161/01. CIR.0000134501.57864.66

38 Raz I, Ceriello A, Wilson PW, et al. Post hoc subgroup analysis of the HEART2D trial demonstrates lower cardiovascular risk in older patients targeting postprandial versus fasting/premeal glycemia. Diabetes Care 2011;34:1511-3. doi:10.2337/dc10-2375

39 US Food and Drug Administration. FDA approves first continuous glucose monitoring system with a fully implantable glucose sensor and compatible mobile app for adults with diabetes. 2018. https:// www.fda.gov/NewsEvents/Newsroom/PressAnnouncements/ ucm611454.htm

40 Baghurst PA. Calculating the mean amplitude of glycemic excursion from continuous glucose monitoring data: an automated algorithm. Diabetes Technol Ther 2011;13:296-302. doi:10.1089/ dia. 2010.0090

41 Medical dictionary for regulatory activities. Homepage. https://www. meddra.org/. Accessed 21 July 2018.

42 Higgins JPT, Green S, eds. Cochrane handbook for systematic reviews of interventions, version 5.2.0. Cochrane Collaboration, updated March 2011. 14 July 2017. https://community.cochrane. org/editorial-and-publishing-policy-resource/cochrane-reviewdevelopment/cochrane-handbooks/cochrane-handbook-systematicreviews-interventions

43 Viswanathan M, Patnode CD, Berkman ND, et al. Recommendations for assessing the risk of bias in systematic reviews of health-care interventions. J Clin Epidemiol 2018;97:26-34. doi:10.1016/j. jclinepi.2017.12.004

44 Lachin JM. Fallacies of last observation carried forward analyses. Clin Trials 2016;13:161-8. doi:10.1177/1740774515602688 
45 Lexchin J. Sponsorship bias in clinical research. Int J Risk Saf Med 2012;24:233-42.

46 Safer DJ. Design and reporting modifications in industrysponsored comparative psychopharmacology trials. J Nerv Ment Dis 2002;190:583-92. doi:10.1097/00005053-20020900000002

47 National Research Council. Panel on Handling Missing Data in Clinical Trials. Committee on National Statistics, Division of Behavioral and Social Sciences and Education. The prevention and treatment of missing data in clinical trials . National Academies Press, 2010.

48 Psaty BM, Kronmal RA. Reporting mortality findings in trials of rofecoxib for Alzheimer disease or cognitive impairment: a case study based on documents from rofecoxib litigation. JAMA 2008;299:1813-7. doi:10.1001/jama.299.15.1813

49 Henry DA, Kerridge IH, Hill SR, et al. Medical specialists and pharmaceutical industry-sponsored research: a survey of the Australian experience. Med J Aust 2005;182:557-60.

50 Gøtzsche PC, Hróbjartsson A, Johansen HK, Haahr MT, Altman DG, Chan A-W. Constraints on publication rights in industryinitiated clinical trials. JAMA 2006;295:1645-6. doi:10.1001/ jama.295.14.1645

51 Manager R. (RevMan). Version 5.3. Copenhagen, Denmark: Nordic Cochrane Center, Cochrane Collaboration; 2012. https://community. cochrane.org/help/tools-and-software/revman-5

52 Liberati A, Altman DG, Tetzlaff J, et al. The PRISMA statement for reporting systematic reviews and meta-analyses of studies that evaluate healthcare interventions: explanation and elaboration. BMJ 2009;339:b2700. doi:10.1136/bmj.b2700

53 Guyatt GH, Oxman AD, Kunz R, et al, GRADE Working Group. GRADE guidelines: 7. Rating the quality of evidence--inconsistency. J Clin Epidemiol 2011;64:1294-302. doi:10.1016/j.jclinepi.2011.03.017

54 Bradburn MJ, Deeks JJ, Berlin JA, Russell Localio A. Much ado about nothing: a comparison of the performance of meta-analytical methods with rare events. Stat Med 2007;26:53-77. doi:10.1002/ $\operatorname{sim} .2528$

55 Fisher DJ, Carpenter JR, Morris TP, Freeman SC, Tierney JF. Metaanalytical methods to identify who benefits most from treatments: daft, deluded, or deft approach?BM/ 2017;356:j573. doi:10.1136/ bmj.j573

56 Guyatt G, Oxman AD, Akl EA, et al. GRADE guidelines: 1. IntroductionGRADE evidence profiles and summary of findings tables. J Clin Epidemiol 2011;64:383-94. doi:10.1016/j.jclinepi.2010.04.026

57 Guyatt GH, Oxman AD, Kunz R, et al. GRADE guidelines 6. Rating the quality of evidence--imprecision. J Clin Epidemiol 2011;64:1283-93. doi:10.1016/j.jclinepi.2011.01.012

58 European Association for the Study of Diabetes. Efficacy and safety of sotagliflozin, a dual SGLT1 and SGLT2 inhibitor, as adjunct to insulin in young adults with poorly controlled type 1 diabetes (JDRF Study). EASD virtual meeting, oral presentation 186. 2017. https://www. easd.org/virtualmeeting/home.html\#!resources/efficacy-and-safetyof-sotagliflozin-a-dual-sglt1-and-sglt2-inhibitor-as-adjunct-to-insulinin-young-adults-with-poorly-controlled-type-1-diabetes-jdrf-study15ae18d4-b8f6-439c-87ea-2f19dcad388e

59 European Association for the Study of Diabetes. A 12-week doseranging study of sotagliflozin, a dual SGLT1 and SGLT2 inhibitor, as adjunct therapy to insulin in type 1 diabetes (inTandem4). EASD virtual meeting, ePoster 186. 2017. https://www.easd.org/ virtualmeeting/home.html\#!resources/a-12-week-dose-rangingstudy-of-sotagliflozin-a-dual-sglt1-and-sglt2-inhibitor-as-adjuncttherapy-to-insulin-in-type-1-diabetes-intandem4-eac92dc0-58bd48ae-9cba-aa1675a947cf

60 Lee AK, Warren B, Lee CJ, et al. The association of severe hypoglycemia with incident cardiovascular events and mortality in adults with type 2 diabetes. Diabetes Care 2018;41:104-11. doi:10.2337/dc17-1669
61 NovoNordisk. Novo Nordisk completes second and final phase 3a trial with liraglutide as adjunct therapy to insulin for people with type 1 diabetes (NN9211). Company announcement 51/2015. https:// www.novonordisk.com/bin/getPDF.1947182.pdf. Accessed 24 October 2018

62 Musso G, Gambino R, Cassader M, Pagano G. A novel approach to control hyperglycemia in type 2 diabetes: sodium glucose cotransport (SGLT) inhibitors: systematic review and meta-analysis of randomized trials. Ann Med 2012;44:375-93. doi:10.3109/078538 90.2011 .560181

63 Monnier L, Colette C, Wojtusciszyn A, et al. Toward defining the threshold between low and high glucose variability in diabetes. Diabetes Care 2017:40:832-8 doi:10.2337/dc16-1769

64 Fanelli CG, Epifano L, Rambotti AM, et al. Meticulous prevention of hypoglycemia normalizes the glycemic thresholds and magnitude of most of neuroendocrine responses to, symptoms of, and cognitive function during hypoglycemia in intensively treated patients with shortterm IDDM. Diabetes 1993;42:1683-9. doi:10.2337/diab.42.11.1683

65 Neuen BL, Ohkuma T, Neal B, et al. Cardiovascular and renal outcomes with canagliflozin according to baseline kidney function. Circulation 2018;138:1537-50. doi:10.1161/ CIRCULATIONAHA.118.035901

66 Heerspink HJ, Perkins BA, Fitchett DH, Husain M, Cherney DZ Sodium glucose cotransporter 2 inhibitors in the treatment of diabetes mellitus: cardiovascular and kidney effects, potential mechanisms, and clinical applications. Circulation 2016;134:752 72. doi:10.1161/CIRCULATIONAHA.116.021887

67 Janssen Research \& Development. Canagliflozin as an adjunctive treatment to diet and exercise alone or co-administered with other antihyperglycemic agents to improve glycemic control in adults with type 2 diabetes mellitus. 11 December 2012. www.janssenlabels. com/package-insert/product-monograph/prescribing-information/ INVOKANA-pi.pdf (accessed 13 September 2014).

68 Neumiller JJ. Empagliflozin: a new sodium-glucose co-transporter 2 (SGLT2) inhibitor for the treatment of type 2 diabetes. Drugs Context 2014:3:212262.

69 Rosenstock J, Ferrannini E. Euglycemic diabetic ketoacidosis: a predictable, detectable, and preventable safety concern with SGLT2 inhibitors. Diabetes Care 2015;38:1638-42. doi:10.2337/dc151380

70 Henry RR, Dandona P, Pettus J, Mudaliar S, Xu J, Hansen L. Dapagliflozin in patients with type 1 diabetes: A post hoc analysis of the effect of insulin dose adjustments on 24-hour continuously monitored mean glucose and fasting $\beta$-hydroxybutyrate levels in a phase Ila pilot study. Diabetes Obes Metab 2017;19:814-21. doi:10.1111/dom.12882

71 Olsen SE, Asvold BO, Frier BM, Aune SE, Hansen LI, Bjørgaas MR. Hypoglycaemia symptoms and impaired awareness of hypoglycaemia in adults with Type 1 diabetes: the association with diabetes duration. Diabet Med 2014;31:1210-7. doi:10.1111/ dme.12496

72 Peters AL, Buschur EO, Buse JB, Cohan P, Diner JC, Hirsch IB. Euglycemic diabetic ketoacidosis: a potential complication of treatment with sodium-glucose cotransporter 2 inhibition. Diabetes Care 2015;38:1687-93. doi:10.2337/dc15-0843

73 Dandona P, Mathieu C, Phillip M, et al. Efficacy and safety of dapagliflozin in patients with inadequately controlled type 1 diabetes (DEPICT-1): 24 week results from a multicentre, double-blind, phase 3, randomised controlled trial [correction: Lancet Diabetes Endocrinol 2017:5:864-76]. Lancet Diabetes Endocrinol 2017:5:864-76.

Web appendix: Supplementary text

Web appendix: Supplementary figures

Web appendix: Supplementary tables 